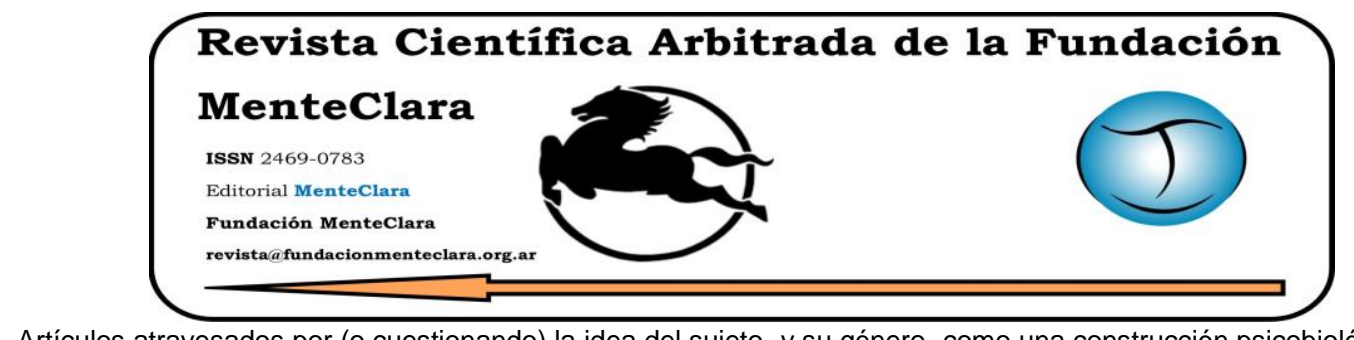

Artículos atravesados por (o cuestionando) la idea del sujeto -y su género- como una construcción psicobiológica de la cultura. Articles driven by (or questioning) the idea of the subject -and their gender- as a cultural psychobiological construction

Vol. 2 (2), 2017

ISSN 2469-0783

https://datahub.io/dataset/2017-2-2-e26

\title{
VIAJANDO POR LOS "CAMINOS DEL SUR»: EL BUDISMO ESOTÉRICO EN EL ASIA MARÍTIMA, SIGLOS VII-XIII D.C.*
}

\author{
TRAVELLING THE 'SOUTHERN PATHWAYS': ESOTERIC BUDDHISM IN MARITIME \\ ASIA, 7TH-13TH CENTURIES AD
}

Andrea Acri a.acri81@gmail.com

Ecole Pratique des Hautes Etudes, Section des Sciences Religieuses, Faculty Member. Institute of Southeast Asian Studies, Nalanda-Sriwijaya Centre, Singapore.

Cómo citar este artículo / Citation: Acri, A. (2017). "Viajando por los "Caminos del sur": El budismo esotérico en el Asia maritima, siglos VII-XIII d. C.". Revista Científica Arbitrada de la Fundación MenteClara, 2(2), 6-62.

DOI: $10.32351 /$ rca.v2.2.28

Copyright: (C) 2017 RCAFMC. Este artículo de acceso abierto es distribuido bajo los términos de la licencia Creative Commons Attribution-Non Commercial (by-cn) Spain 3.0. Recibido: 25/04/2017. Aceptado: 29/05/2017 Publicación online: $30 / 10 / 2017$

Conflicto de intereses: Ninguno que declarar.

\section{Resumen}

Este artículo presenta un panorama histórico de las redes de sitios y agentes que fueron instrumentales en la creación y circulación de las diferentes variedades de budismo esotérico (o tántrico) entre los siglos VII y XIII hasta su casi desaparición. El autor aborda el estudio del budismo esotérico desde una perspectiva geográfica amplia, hace hincapié en las interacciones maritimas que se produjeron a través de las llamadas "Rutas Marítimas de la Seda" en el curso de varios siglos y avanza en una narrativa histórica complementaria que toma las conexiones marítimas. Basado en evidencias textuales, materiales y arqueológicas diseminadas en toda el Asia marítima, muestra cómo migraron los maestros budistas tántricos de la "primera ola" a distintos puntos del Asia, donde evolucionaba y se consolidaba el nuevo paradigma 
tántrico gracias al patrocinio de dinastías como las de los Śailendras, Yarlung y Tang. Durante la expansión de la "segunda ola", los cultos tántricos que giraban en torno a aspectos sumamente esotéricos y militares de las deidades (como Heruka y Hevajra) tuvieron como seguidores al Kublai Kan en la China, a Kṛtanagara en Java oriental y a Jayavarman VII en Camboya, entre otros, hasta su posterior desaparición. El trabajo sostiene que aparte de las contingencias sociopoliticas, tales cambios de paradigma pueden haber ocurrido como resultado de "reformas" religiosas que promovieron un giro hacia las variedades no esotéricas -es decir, variantes mágicomísticas- de las tradiciones budistas (como sucedió, por ejemplo, en Sri Lanka $\mathrm{y}$, en una fecha posterior, en Myanmar y Camboya con respecto a la prevalencia del budismo Therāvada sobre el Mahāyāna y Vajrayāna o incluso diferentes religiones como sucedió, por ejemplo, en Java Central). Finalmente el artículo sienta las bases para continuar los estudios académicos para identificar las redes de practicantes no institucionalizados que contribuyeron a la difusión de las formas del tantrismo en el Asia marítima.

\section{Abstract}

This article presents a historical overview covering the networks of places and agents that were instrumental to the rise and spread of the different varieties of Esoteric (or: Tantric) Buddhism between the 7th and 13th centuries until near vanishing point. The author approaches the study of Esoteric Buddhism from a broad geographical perspective, emphasizing the maritime interactions that took place through the socalled "Maritime Silk Routes" over the course of several centuries, and provides with a supporting historical narrative based on maritime linking. On the basis of textual, material, and archaeological evidence disseminated throughout all Maritime Asia, the author shows how Tantric Buddhist masters of the "first wave " migrated to different Asian locations, where the new Tantric paradigm was developed and consolidated thanks to the sponsorship of dynasties such as the Śailendras, the Yarlungs, and the Tangs. During the " second wave " of expansion, Tantric cults revolving around highly esoteric and martial aspects of deities (such as Heruka and Hevajra) were followed by Kublai Khan in China, Krtanagara in East Java, and Jayavarman the VII in Cambodia, among others, until they eventually disappeared. This work argues that beyond socio-political contingencies, paradigm changes may have occurred as a 
result of religious "reforms" which promoted a shift towards non-esoteric varieties that is, mystical-magical variants - of Buddhist traditions (as happened, for example, in Sri Lanka and, at a later date, in Myanmar and Cambodia as regards the prevalence of Theravāda Buddhism over Mahāyāna and Vajrayāna, or even different religions as happened, for example, in Central Java). Finally, the article sets a starting point to pursue further research to identify networks of non-institutionalized practitioners who contributed to the spread of forms of Tantrism across Maritime Asia.

\section{Palabras Claves/ Keywords}

tantra; tantrismo; budismo; budismo esotérico; tántrico; estudios tántricos; paradigma tántrico; ruta marítima de la seda; Asia Maritima; tantrism; Buddhism; tantric studies; tantric paradigm; Southeast Asian Studies; Silk Road Studies; Tibetan Buddhism; Indian Ocean World.

\footnotetext{
* Este artículo es una traducción al español ralizada por Rocío Silveira de Andrade y Oscar R. Gómez, para la Fundación MenteClara, de una versión en inglés revisada y ampliada por el autor (Andrea Acri) de "Chapter 1. Introduction: Esoteric Buddhist Networks along the Maritime Silk Routes, 7th- 13th Century AD", in A. Acri (ed.), Esoteric Buddhism in Mediaeval Maritime Asia: Networks of Masters, Texts, Icons, Singapore: ISEAS Publishing, 2016, pp. 1-26.
} 


\section{Introducción}

En la época medieval, ${ }^{1}$ las ciudades estados de la costa y del interior, extendidas sobre una región geográfica amplia aquí llamada "Asia maritima", fueron conectadas por una red entre las ciudades puertos que conectan al Océano Índico, al Pacífico occidental y al mar de China meridional.

Esas localidades cosmopolitas actuaron no solo como encrucijada del poder político y del espíritu emprendedor mercantil, sino también como centros de aprendizaje, culto y peregrinación, donde las tradiciones institucionalizadas del hinduismo y del budismo coexistieron lado a lado.

Desde principios del siglo VII, los monjes que se adhirieron a los mandala y las modas esotéricas centradas en el ritual dentro de la corriente Mahāyāna viajaban por las rutas maritimas, convirtiéndose en los vectores para la circulación de textos esotéricos, rituales e iconos.

Este estudio presenta un panorama histórico de las redes de sitios y agentes que fueron instrumentales en la creación y circulación de las diferentes variedades de budismo esotérico.

Un creciente reconocimiento del importante papel que desempeñaron las rutas marítimas -las denominadas "Rutas marítimas de la Seda"- en la configuración de la conectividad premoderna intraasiática, impulsa el estudio del budismo esotérico desde una perspectiva geográfica amplia, haciendo hincapié en las interacciones maritimas que se produjeron a través de los límites geográficos y culturales en el curso de varios siglos. Estableciendo así el constitutivo e importante papel desempeñado por el "sur" del litoral y las regiones insulares -y especialmente el sudeste de

\footnotetext{
${ }^{1}$ Esta es la periodización ampliamente utilizada que se refiere al periodo post-Gupta de la historia del sur de Asia (Davidson, 2002). Extiendo la aplicación del término "medieval" al área más amplia del Asia maritima, como lo hicieron Sprengard y Ptak (2004), y también Wong y Heldt (2014) con respecto a China, "Como un gesto hacia una historia más global"; Compare en Abu-Lughod (1989) y Pollock (2006) la aplicación del término en el mundo eurasiático.
} 
Asia- en la génesis y propagación del budismo tántrico -esotérico- a través de Asia.

Esta perspectiva revela los limites que tiene una historiografia que se basa exclusivamente en las "vias septentrionales" terrestres de transmisión de las variedades esotéricas del budismo a través del continente eurasiático, y avanza en una narrativa histórica complementaria que toma las "vias del sur", es decir: Las conexiones basadas en el mar.

\section{Imagineria del budismo esotérico en la región maritima medieval}

\section{de Asia}

El Asia marítima puede ser conceptualizada como una agrupación socioespacial o región del mundo (Lewis y Wigen, 1997) constituida por un patrón de relaciones siempre cambiantes dominadas por afinidades básicas subyacentes.

En el período medieval, esta región comprendía una red de estados costeros e interiores, conectados entre sí a través de una red de ciudades portuarias cosmopolitas a través de la Bahía de Bengala / Océano Índico y el Mar de China Meridional / Océano Pacífico Occidental, formando un único océano (Wolters, 1999) o, más bien, un «Mediterráneo de dos océanos" (Wang, 2015).

Habiendo sido el teatro de la circulación de personas, mercancias, idiomas e ideas, a través de las rutas marítimas durante milenios, el Asia marítima puede ser teorizada como la formación -como Eurasia- de una red interconectada con un fondo común de historia humana, intelectual y ambiental.

Como lo demuestran los materiales históricos, epigráficos y de arte histórico, los cultos budistas esotéricos, las imaginerías y las tecnologías 
rituales, florecieron en el Asia marítima desde principios del siglo VII. Accesorios Vajra, iconos de deidades esotéricas y dhāraṇis basados en textos esotéricos del sánscrito budista, se han recuperado a través de una vasta extensión de territorio litoral e insular del sur de Asia.

Las evidencias encontradas en Sri Lanka, ${ }^{2}$ las Maldivas, ${ }^{3}$ el archipiélago indonesio ${ }^{4}$ y las Filipinas, ${ }^{5}$ muestran la existencia de un tráfico multidireccional entre los centros del sur, sudeste y este de Asia, que actúaron como nodos interconectados que contribuyeron a la génesis y la circulación del budismo esotérico.

Aunque el aura religiosa y el prestigio político de los centros del budismo del sur de Asia siguieron siendo fuertes a través del período medieval, las regiones exteriores de la cosmópolis budista trataron de vincularse a estos centros, convirtiéndose así en centros con respecto a las nuevas "periferias" creando a medida que las redes se movian y las fronteras budistas se extendian lo que Sen (2014b) ha descrito como la aparición de "múltiples centros del discurso budista".

\subsection{Asia meridional}

El subcontinente Indio acogió lo que puede considerarse varias "cunas" del budismo esotérico. Esas localidades se encontraban a lo largo de los litorales occidentales y orientales de la India $\mathrm{y}$ en sus territorios interiores, especialmente el Deccan occidental, el área de Gran Bengala, Andhra Pradesh y Odisha, Tamil Nadu y la isla de Sri Lanka.

\footnotetext{
2 Véase Mudiyanse 1967; Chandawimala 2013; Sundberg 2014.

3 Véase Gippert 2004, 2005.

${ }^{4}$ Véase Acri 2016b; Cruijsen, Griffiths y Klokke 2012; Griffiths 2011b, 2012, 2014a, 2014b, 2014c; Griffiths, Revire and Sanyal 2013; Hall 2010; Kandahjaya 2009, 2016; Largo 2014; Miksic 2016; Nihom 1994, 1998a; Sundberg 2003.

5 Véase Francisco 1963a, 1963b, 1963c; Capistrano-Baker 2011; Orlina 2012.
} 


\subsubsection{La India occidental}

Los vestigios budistas esotéricos más tempranos e importantes se encuentran en la India occidental, como se pone de manifiesto, por ejemplo, por imágenes de las cuevas budistas de finales del siglo VI y principios del siglo VII en el Deccan occidental, como Ellorā. (Malandra, 1996), Aurangabad (Brancaccio, 2010) y Kānherī, donde Tārās y Avalokiteśvaras -esotéricos- se encuentran ya en los siglos VI-VII (Pandit, 2015) (Bopearachchi, 2014).

Esos primeros sitios, donde los Ocho Grandes Bodhisattvas (aștamahābodhisattvas) del Mahāyāna desarrollado ocupan una posición prominente en la iconografia, muestran el naciente pensamiento e imágenes tántricas budistas (Malandra, 1996) (Linrothe, 1999). De acuerdo con Wayman y Tajima (1992), un tantra budista temprano y seminal tal como el Vairocanābhisambodhi pudo haber sido compuesto a mediados del siglo VI en Maharashtra.

La circulación de los iconos budistas -y textos- entre los sitios de la India oriental y los sitios del sudeste asiático puede ser la hipótesis sobre la base de alineaciones iconográficas y desarrollos doctrinales.

La costa de Konkan parece haber sido un bastión del budismo esotérico en el siglo XI. El conocido manuscrito nepalés ilustrado del Aștasāhasrikā-Prajñāpāramitā de 1015 d. C. -CUL Ms. Add. 1643, citado por (Mitra, 1971)- que presenta una documentación visual de divinidades y centros reconocidos a través del Asia budista, menciona Mahāviśva ¿una corrupción de Mahābimba?- como la sede de un famoso Lokanātha (Szántó, 2016), y enlaza un número significativo de otros sitios budistas con Kon̉kana (Kim, 2014).

El colofón del siglo IX de Cakrasaṃvarapañjikā (Sugiki, 2001) del Jayabhadra cingalés -que posteriormente se convirtió en vajrācārya en 
Vikramaśîla- registra su presencia en esa región y menciona un monasterio budista que alberga una famosa caitya -templo budista funerario- y un templo de Tārā en Mahābimba. Tāranātha reporta la misma información (Chattopadhyaya, 1980).

\subsubsection{Noreste de la India}

Se reconoce generalmente que los principales centros del budismo esotérico -y del tantrismo en general- se encontraron en las regiones del noreste del subcontinente indio, que corresponde aproximadamente al Bihar moderno -que es la cuna del budismo desde la época del Buda-, Bengala Occidental y Bangladesh.

Bihar fue el asiento de prestigiosas instituciones de enseñanza budista como Nālandā, Vikramaśîla, Somapura y Uddanḍapura -Otantapurī-, donde las modas esotéricas parecen haberse popularizado desde finales del siglo VIII hasta el siglo XII (Saran, 1981) (Tanaka, 2008) (Sanderson, 2009) (Decleer $\mathrm{n} / \mathrm{p}$ ).

Toda la región nororiental acogió a los principales maestros del budismo Mantranaya y Vajrayāna y se cree que varias obras tántricas se originaron desde alli.

Nālandā constituyó el nexo -real o imaginario- que enlazó muchos de los agentes primarios de la "primera ola" del budismo esotérico en el siglo VIII y en el siglo IX se convirtió en "el centro de una nueva red tántrica en Asia" (Hall, 2010). 


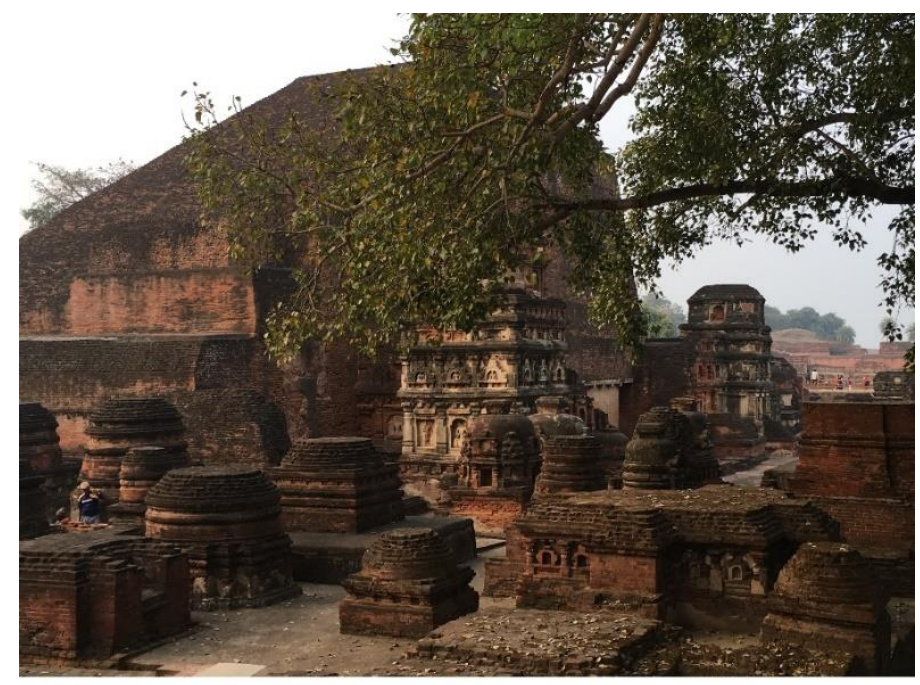

Stūpa de Sāriputta, Nālandā, Bihar. C Andrea Acri

Conectados a la ciudad portuaria de Pāla de Tāmralipti, Nâlandā-y los otros centros budistas en la región noreste- eran fácilmente accesibles a través de las rutas maritimas que conectaban el litoral de la Bahía de Bengala, el sudeste de Asia y China.

Fue en Nālandā que Śubhākarasimha, Vajrabodhi y Prajña fueron instruidos y recibieron su ordenación antes de emprender la carrera de maestros viajeros. Aparte de ser un ilustre centro de aprendizaje budista, Nālandā fue también la potencia cultural que dictó el paradigma religioso y estético predominante en la cosmópolis budista del siglo VIII al siglo XIII.

Esto también es sugerido por el uso de Siddhamātrkā -una variedad de escritura del norte-este-indio, en uso en Nālandā- en tierras extranjeras, a saber, en corpus textuales budistas esotéricos extensos de China ${ }^{6}$ y Japón, así como inscripciones budistas esotéricas de Sri Lanka, el archipiélago indonesio y la península malaya.

\footnotetext{
6 P.C. Chakravarti (Majumdar, 1971: 662), citando a Plinio y el relato del peregrino chino Faxian, menciona que el viaje en un buque mercante desde la ciudad portuaria de Pāla de Tāmralipti a Sri Lanka (camino hacia el sudeste asiático y China) duro solo 15 dias. Yijing cuenta que treinta y siete de los sesenta monjes chinos que fueron al subcontinente indio viajaron por mar en buques mercantes; además, afirma que su propio viaje desde Cantón a Sumatra tardó un mes, mientras que el tramo restante de Kedah en Malasia peninsular a las islas de Nicobar tomó diez días, y de allí a Tāmralipti tomó quince días (Ray, 2008: 124). Pero según otras fuentes, debido a la dirección predominante de los vientos de monzón, era casi imposible hacer un viaje de regreso entre China y el subcontinente indio en un año (Jordaan y Colless, 2009: 112).
} 
El nombre evocador de Nālandā resonó en el sudeste asiático: el rey sumatra Bālaputradeva, que aparentemente estuvo involucrado en la lucha dinástica que tuvo lugar en Java Central a mediados del siglo IX, es mencionado en una inscripción publicada por Devapāla en Nālandā, que registra su patrocinio de un vihāra para el uso de los peregrinos de Śrīvijaya. ${ }^{7}$

Además, existen vínculos bien conocidos entre los maestros de los dominios Pāla y el budismo patrocinado por Śailendra en Java.

Piensen en Kumāraghoṣa, el preceptor real de Gaudìdvīpa, que instaló una imagen de Mañjughoșa (Mañjuśrī) a petición del rey Śailendra Śrī Sañgrāmadhanã̃jaya (Sarkar, 1971), y el golapaṇditā / gaudapaṇditā que figura en la inscripción sin fecha de Pasir Panjang en Karimun Besar en el archipiélago de Riau, que podría haber sido grabada por un monje de Bengala continental, Sumatra o Java (Caldwell y Hazlewood, 1994).

En dos inscripciones balinesas del siglo $\mathrm{X}$ relacionadas con el preceptor budista - upādhyāya- Dhanavan (Ardika, 2015) (Goris, 1954) se menciona una localidad llamada Nālandā (nalonda, nalanda), junto con Vārānasī.

Como señala Ardika (Op. Cit.), esas inscripciones balinesas indican que los topónimos asociados con centros prestigiosos del budismo en el subcontinente fueron trasladados a lugares locales.

\footnotetext{
7 Véase H. Sastri 1923-24. En la placa de cobre, la reina madre de Bālaputra se identifica con Tārā ("Tārā era la reina de ese rey, y era la hija del gran gobernante Dharmasetu de la raza lunar y se parecía a Tārā misma" [tāreva], (Sastri, 1923). El mismo símil se encuentra en una línea fragmentaria en la inscripción en sánscrito en escritura Siddhamātrkā de Plaosan en Java Central, donde se dice que la esposa de una figura real no identificada aparece / resplandece "como Tārā" (tāreva virājati) (Long, 2014).
} 


\subsubsection{Odisha}

Ahora se reconoce cada vez más que Odisha desempeñó un papel significativo en la formación del budismo esotérico y su propagación al sudeste asiático (Mishra, 2005) (Patra, 2013) (Patnaik, 2014) y, quizás, a China también. ${ }^{8}$

Esta región, conocida anteriormente como Kalinga o Oḍra / Uḍra, era un centro histórico monástico y lugar sagrado de peregrinación, como Ratnagiri, Udayagiri y Lalitagiri, que estaban conectados a las redes marítimas a través de los puertos de Kalingapatana y Puri. ${ }^{9}$

El Ratnagiri mahāvihāra fue un centro prominente para el estudio de los textos tántricos. Por ejemplo, Szántó (2016) informa que el Saḿvarodayā -el hasta ahora único manual de iniciación superviviente del ciclo Samvara, copiado en un manuscrito nepalés con fecha de 1054 d. C.- fue escrito por un cierto Bhūvācārya en Ratnagiri.

Los Anales Azules tibetanos se refieren a que el maestro Odishan Celuka -Tsi-lu-pa- leyó el Kālacakra en el mismo monasterio, que quedó intacto luego de las invasiones turcas (Roerich, 1953). Otras fuentes tibetanas confirman la conexión entre Celuka y Ratnagiri, así como Nālandā y Vikramaśîla (Donaldson, 2001).

La cara trasera de la imagen en khondalita de un Abhisambodhi Vairocana en Lalitagiri -siglo VIII- contiene una porción de un mantra del sexto capítulo del Mahāvairocanasūtra, uno de los tantras budistas más importantes; este texto fue transmitido a China en el siglo VIII por Śubhākarasimha, una figura con pedigrí real nativo de Odisha (Mishra,

\footnotetext{
8 Según el texto chino Sung kao-seng chuan de Zanning (919-1001), el rey de Oḍra Shan-wu-wei o Subhakarasimha (660-758 dC) introdujo Tantrayāna en China (Mishra, 2016) (Donaldson, 1995). Véase también más adelante sobre la introducción del Gaṇdavyūha-Bhadracarī a China por un rey de Odra.

9 Véase Malandra 1996: 186 n. 12, 204; Sadakata 1997; Donaldson 2001; Ray 2008: 130 - 33; Sanderson 2009: 80-83; Mishra 2011; Reichle 2016.
} 
2016). ${ }^{10}$ Tanaka (2014) describe algunos dhāranīs desenterrados en Udayagiri II que no se han encontrado en ninguna otra parte de la India, pero existen versiones en Sri Lanka, Tibet, China y Japón. ${ }^{11}$

E1 Āryasarvatathāgatādhișthānahrdayaguhyadhātukaraṇ̣amudrā nāma dhāraṇi sobre la losa de piedra No. 27 en Udayagiri II proporciona evidencia de la conexión entre Śubhākaradeva de la dinastía BhaumaKara y Udayagiri (Op. Cit., pp. 151-161).

Un Samantamukhapraveśa dhārañi -o Vimaloṣnịṣa dhāraṇi- está grabado en la parte posterior de las imágenes de Lokeśvara en Udayagiri II y Ratnagiri (Mishra, 2016).

Las hipótesis sobre la conexión entre los javaneses de la dinastía Śailendras y las dinastías indias, tales como los Śailodbhavas del Odisha del siglo VII o los Ikșvākus de Śrīśailam / Śrīparvata de Andhra (Majumdar, 1937) (Sarkar, 1985ª y 1985b) (Lokesh Chandra, 1995), y la identificación del asiento tántrico de Oḍ̣iyāna con Odisha en lugar del Valle de Swat (Donaldson, 1995 y 2001) ahora han sido abandonados en gran parte. Sin embargo, una mayor investigación sobre los antiguos vinculos culturales entre Odisha y el sudeste de Asia sigue vigente.

Emigh (1996) propuso una posible influencia de las prácticas tántricas de Odisha en las figuras demoníacas de la danza-teatro balinesa. Reichle (2016) ha puesto de manifiesto ciertas similitudes iconográficas entre Ratnagiri Mahāvihāra y el javanes central Candi Mendut, es decir, el papel desempeñado por Pãñcika y Hārītī, la presencia del mandala del Gran Bodhisattva, así como del Buda sentado central por Avalokiteśvara y Vajrapāni. Y Roy Jordaan ha sugerido una correspondencia entre el

\footnotetext{
10 A Śubhākarasimha se le atribuye haber traducido y transmitido a China otros textos esotéricos importantes como el Subāhupariprcchā, Susiddhikāramahātantrasaddhanopāyikāpatạla, y (menos seguramente) manuales rituales relacionados con el Sarvatathāgatatattvasangraha y Vijayosnīsa. Sobre el origen real y la genealogía de Śubhākarasimha, véase más abajo, n. 28.

11 Esto fue traducido al tibetano en el siglo VIII (Peking Canon 141, 508) y llevado a China por Amoghavajra en el VIII siglo (T 1022), también por Dānapāla en el X siglo (T 1023) (Mishra, 2016).
} 
arreglo de las deidades en la superestructura de Candi Kalasan y un maṇdala en Ratnagiri (Jordaan, 1998).

De manera similar, se ha sugerido que la representación de la secuencia de Gaṇdavyūha-Bhadracarī en los relieves de Borobudur se ajusta mejor en ciertos detalles al texto traducido por Prajña en Chang'an en 796-798, que podría haber llegado a Java desde Odisha. Las escrituras fueron reunidas en el siglo VIII y enviadas por el gobernante de Uḍra al emperador de China en 795 o, alternativamente, de China a través del monje javanés Bianhong, quien pudo haber estudiado el texto con Prajña en Chang'an (Woodward, 2009).

\subsubsection{Andhra Pradesh}

Un escenario evocador en el mundo tántrico panasiático a través de la división Bauddha-Śaiva fue Śrīsailam / Śrīparvata en Andhra Pradesh (Yamano, 2009) (White, 1996).

White discute las estrechas asociaciones de Śrīsailam / Śrīparvata con los siddhas y las tradiciones esotéricas / alquímicas ${ }^{[\mathrm{N}}$ del $\left.\mathrm{E}\right]$-incluidas las que provienen de Nāgārjuna- tanto en la tradición budista como Śaiva, y señala que puede haber habido dos topónimos separados. Uno en el distrito de Kurnool de la meseta central de Deccan, y otro a sesenta millas al este, cerca de Nāgārjunakoṇda -otro centro de larga data e importancia del budismo-12

\footnotetext{
12 Véase White 1996: 375, n. 47, en referencia a una obra anterior de Arion Roşu. Sobre las características esotéricas de algunos sitios budistas tempranos en Andhra, véase Ray 2008: 128-30.

[N del Editor] Nāgārjuna fue, probablemente, el autor del texto Rasaratanakaram que es un compendio de formulaciones proto-químicas similares a las descriptas en textos Rasayana de las escuelas tántricas Kaula. En los mismos se ven aspiraciones y hallazgos, similares a los descritos por los alquimistas medioevales europeos y es por eso se menciona una "alquimia indú" budista y shivaíta.
} 
Lokesh Chandra (1993a) ha identificado esto como el "Vajraparvata" mencionado en la crónica cingalesa Nikāyasañgraha del siglo XIV como sede de los monjes heréticos Vājïiyavāda y Nīlapațadarśana, que introdujeron variedades de budismo tántrico en la isla en el siglo IX.

El área de Śriśailam, conectada al importante puerto marítimo de Viśakhapatnam, era "un punto de partida para los misioneros en Cachemira, China, Bengala y Sri Lanka" (White, 1996).

\subsubsection{Sur de la India y Sri Lanka}

Otras localidades del sur de Asia que actualmente no están comúnmente asociadas con el budismo, o que están asociadas con el budismo Theravāda / Pali, también están siendo reconocidas como centros prominentes -si no son cunas, de hecho- de actividades budistas esotéricas en el período medieval temprano.

Estos son los predominantementes: Śaiva Sur de la India -Kāncī y Nākappațtinam en Tamil Nadu en particular-, y Sri Lanka. Esas localidades actuaron como centros para la difusión de tradiciones esotéricas al sudeste asiático y más allá.

Claire Holt (1991) argumentó que las regiones de Pallava del sur de la India, Sri Lanka y el sudeste de Asia "constituian un verdadero triángulo cultural desde el VII al IX siglon; destacando la influencia panasiática de la díada cultural de Pallava India y Śrī Lan̉kā en el siglo VIII.

Jeffrey Sundberg y Rolf Giebel (2011) se enfocan en el estatus de algunas sectas budistas que operaron en Kāncī, en el cingalés Abhayagirivihära y en su réplica javanesa central, como custodios de textos esotéricos y enseñanzas orales que desempeñaron un papel clave en la configuración del paradigma budista esotérico -tántricopanasiático medieval. 
Las investigaciones científicas de los restos arqueológicos confirman la información encontrada en fuentes sánscritas, tibetanas y chinas, de que tanto el sur de la India como Sri Lanka hospedaron antiguos linajes importantes de maestros budistas esotéricos y repositorios de tantras.

Las escrituras fundamentales, como el Mahāvairocanatantra y Sarvatathāgatatattvasangraha, pueden haber sido compiladas alli (Hodge, 2003). De acuerdo con la hagiografia Budista esotérica, Nāgārjuna -uno de los Mahāsiddhas a menudo asociado con el sur de la India en fuentes sánscritas medievales- recibió sus textos revelados de Vajrasattva en una stūpa de hierro y luego los transmitió a Nāgabodhi también llamado Nāgabuddhi (Sinclair, 2016b)- en el sur de la India (Orzech, 1995).

Monjes del calibre de Punyodaya, Amoghavajra y Prajña ${ }^{13}$ viajaron desde China al sur de la India y / o Sri Lanka, para hacerse de algunos raros textos esotéricos y recibir la iniciación de los maestros de consagración locales.

Lokesh Chandra (1993a) ha subrayado la importancia de Kāñcī -que él conecta con Oḍ̣iyāna- para el budismo esotérico de ultramar -y especialmente insular del sudeste Asiático- (Guy, 2004) (Monius, 2001).

El rey Narasimhapotavarman -es decir, Narasimhavarman II Rājasimha que reinó entre 700-728- de Kāñcī concedió a Vajrabodhi protección especial y envió a su general "Mizhunna» (ch. 米准那) junto con él a China en una misión diplomática. Tan amigables fueron las relaciones entre los Pallavas y la corte Tang en ese período que el mismo rey construyó una pagoda budista en Nākappatținam en honor del emperador chino, permitiéndole a el asignarle el nombre (Seshadri, 2009). Por otra parte, a través de un vínculo Pallava, Vajrabodhi, con motivo de su visita a Sri del sur de la India y estaba bien versado en la tradición Vidyādhara / Dhāraṇī de esa región. 
Lanka en su camino a China, gozó de la protección del Rey Mānavarman -Śrīsîla de la biografia de Vajrabodhi-, que antes de su coronación en el 684 pasó un largo exilio en Kāñāi sirviendo como general (Sundberg y Giebel, 2011).

Como sostienen estudios recientes, los lazos diplomáticos entre las monarquías Pallava y Tang sirvieron como "un contexto explicativo para el fácil acceso de Vajrabodhi al santuario interno de la corte Tang" (Sundberg y Giebel, Op. Cit.).

Aunque Sri Lanka fue uno de los primeros receptores y exportadores del budismo Theravāda / Pali, estudios recientes han subrayado los numerosos vestigios de Mahāyāna y del budismo esotérico existente en la isla. Estos incluyen imágenes de Vajrasattva y Tārā, tablillas votivas con elementos de Vajrayāna, fragmentos de Ratnakūța Sūtra encontrados en el Monasterio de Cețiyagiri, Dhāranīghara mencionados en Mahāvaṁsa, dhārañis de Abhayagiri y los encontrados en el Gran Libro de la Protección (Mudiyanse, 1967) Sundberg, 2004, 2014 y 2016) (Sundberg y Giebel, 2011) (Chandawimala, 2013).

El mencionado Nikāyasangraha atribuye la introducción del budismo esotérico en Sri Lanka a un monje del linaje de ordenación Vajraparvata, y su adopción por Matvalasen, es decir, el rey Sena I (r 834-54). ${ }^{14}$

Curiosamente, ese texto también contiene una lista rara e importante de las primeras escrituras budistas esotéricas supuestamente seguidas por los monjes que vivian en Vajraparvata, tales como los textos seminales Sarvatathāgatatattvasatravagrama, Māyājāla, Paramādya y Cakraśamvara. (Lokesh Chandra, 1993b). Esta lista apoya la opinión de que en los medios budistas de Sri Lanka -es decir, en el mismo Abhayagirivihāra- se encontraron repositorios de textos esotéricos no

14 Véase Sankrityayana 1934: 214-16; Mudiyanse 1967: 9; Lokesh Chandra 1993a y 1993b: 118-26; Sundberg y Giebel 2011: 215, n. 168; Chandawimala 2013: 117). 
disponibles en China, y tal vez incluso inaccesibles a los viajeros a la India.

Como argumentó Sundberg y Giebel (2011), fue la búsqueda de estos textos, y el deseo de recibir abhiṣeka en un linaje cingalés aparentemente asociado con Nāgabodhi o Ratnabodhi (ch. Baojue 寶 覺), que llevó a Amoghavajra a Viajar a Sri Lanka desde China siguiendo las huellas de su maestro Vajrabodhi. ${ }^{15}$

Prajña también volvió al sur de la India desde China para buscar textos esotéricos pertenecientes a tradiciones de Vidyādhara (ch. 持 明) y estudió técnicas yóguicas bajo el maestro de consagración Dharmayaśas -en chino Damoyeshe 達摩耶 舍 (Orzech, Sørensen y Payne 2011b).

Las interacciones entre Sri Lanka y los centros de tantrismo patrocinados por los Pālas están bien documentadas (Sen 2014a). De acuerdo con Tāranātha (Chattopadhyaya, 1980), el Jayabhadra de Sri Lanka, uno de los primeros exegetas del Laghusamvara / Herukābhidhāna, fue vajrācārya en Vikramaśīla. ${ }^{16}$ La influencia de Nālandā puede ser detectada en el enigmático Rājịnāvihāra, un templo de estilo Pallava del siglo VIII construido en un lugar al norte de Kandy, que ahora lleva el nombre de Nālandā.

\footnotetext{
15 En la p. 190 los autores, refiriéndose a la biografia de Hanguang (T 2061.879b18), mencionan a Samantabhadra cingales como el iniciador "final" de Amoghavajra (Chou, 1945) (Lokesh Chandra, 1993b). Otras biografias mencionan Nāgajñāna (es decir, Nāgabodhi / Nāgabuddhi 龍 智) y Ratnabodhi (Sundberg y Giebel, 2011) (Sundberg, 2014).

16 Sanderson (2009) sitúa su mandato entre 880-92.
} 


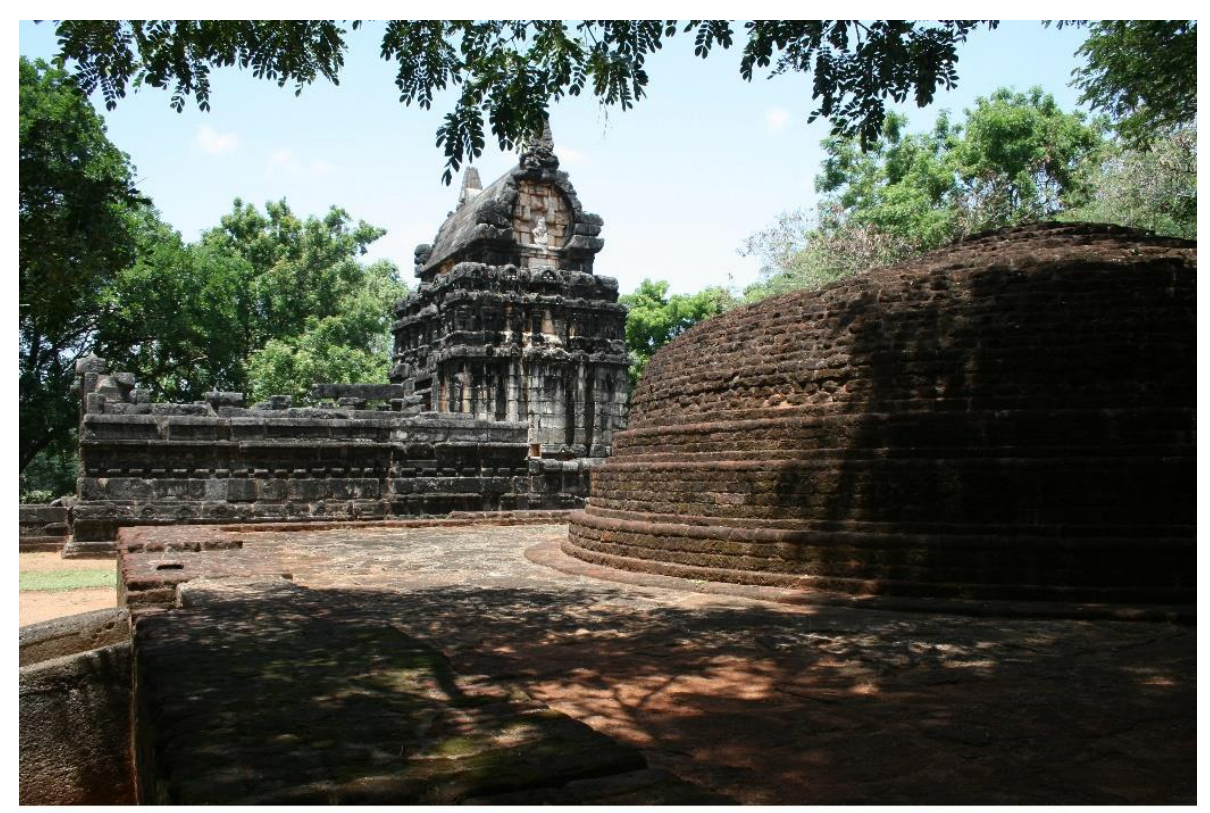

Rājiṇāvihāra, Sri Lanka. (c) Andrea Acri

El templo -gedigē- presenta relieves eróticos de carácter transgresor (Mudiyanse, 1967) (Chandawimala, 2013) y Dohanian (1977) se refiere a la existencia de una breve inscripción en Siddhamātrkā del siglo IX encontrada cerca (Sundberg, 2016).

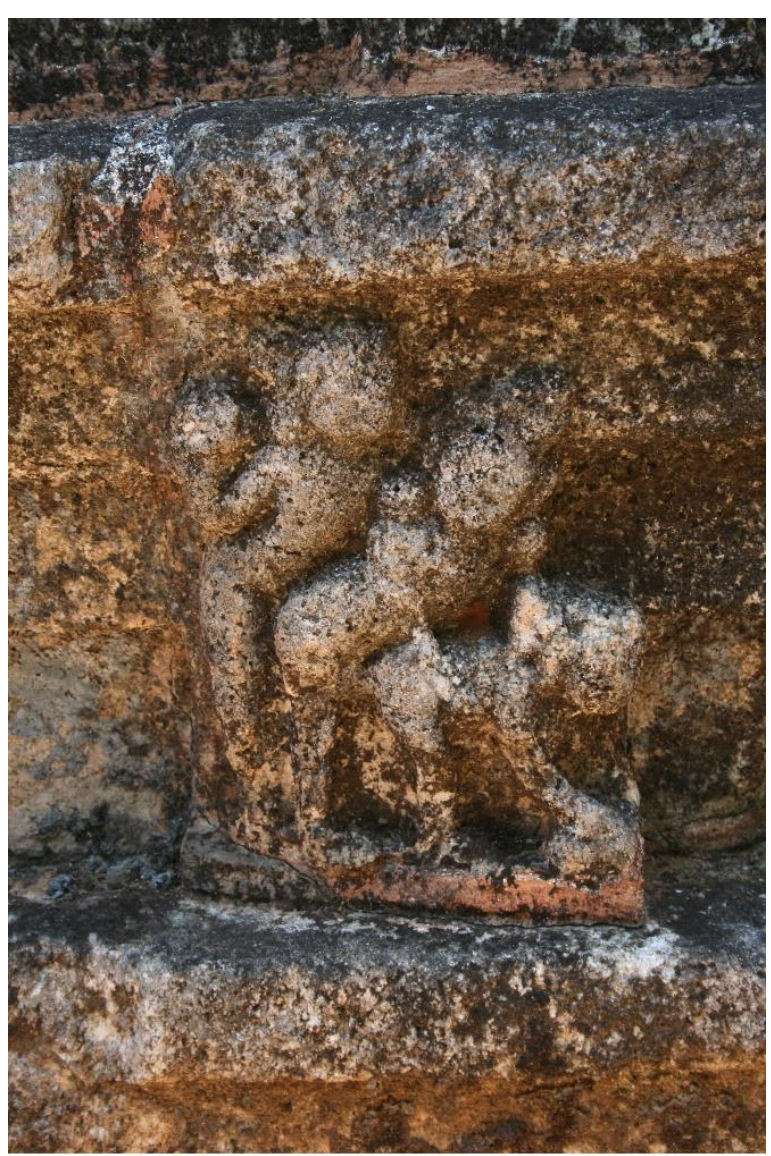

Relieve en Rājināvihāra. (C) Andrea Acri 
La fama del Abhayagirivihāra en Anurādhapura se extendió hasta el sudeste asiático. Como lo prueba una inscripción ${ }^{17}$ en siddhamātrkā del siglo VIII, los Śailendras construyeron una delegación del Abhayagirivihāra de Sri Lanka, aparentemente destinada para el uso de monjes budistas cingaleses de mentalidad esotérica, en el promontorio de Ratu Boko en Java Central; como lo demuestran Miksic (1993-94), Degroot (2006) y Sundberg (2004, 2011, 2016), las estructuras relacionadas con el Abhayagirivihāra de Ratu Boko comparten con sus prototipos cingaleses, es decir, algunas de las estructuras periféricas de Abhayagiri aparentemente poblados por monjes ascéticos, motivos arquitectónicos comunes, como plataformas de meditación doble.

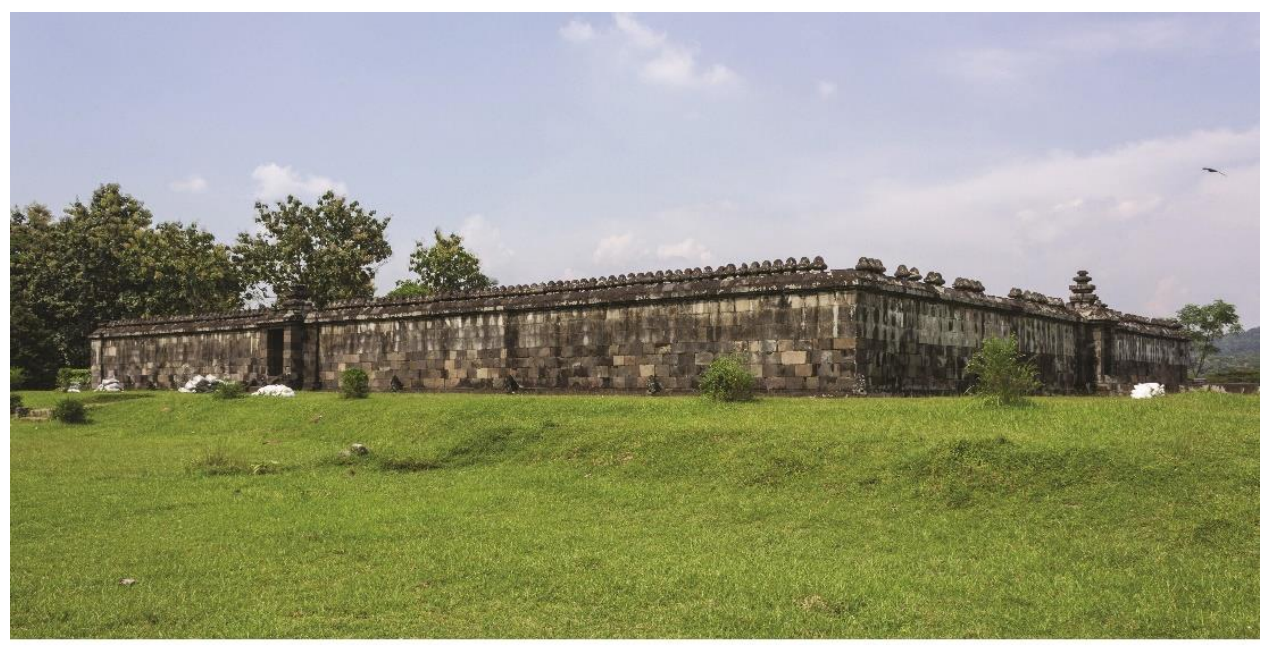

Caras norte y oeste de la pared prākāra alrededor de la estructura de doble plataforma, Ratu Boko, Java Central. (C) Crisco 1492, Wikimedia Commons

De hecho, el área en la llanura de Kedu donde se construyó Candi Sewu y el complejo del templo de Prambanan parece haber sido llamada Lan̉kapura para entonces, como si recreara una "réplica"-budista- local de Sri Lanka; Griffiths (2013) plantea la hipótesis de la existencia de "Abhayagiris múltiples en más de una parte del sudeste de Asia, en el sur de Camboya, en el sur de Vietnam, en la península de Tailandia, además del de Javar.

17 Véase Casparis 1950: 11-22, 1961; Lokesh Chandra 1993a; Sundberg 2004, 2016. 


\subsection{Sudeste Asiático}

Situada en la intersección geográfica entre el sur de Asia y el este de Asia, la región étnica, lingüística y culturalmente diversa del sudeste asiático -y del archipiélago indonesio en particular- era un área geográfica estratégica que ha producido vestigios significativos de su glorioso pasado budista, todavía poco representada en la erudición contemporánea.

Lejos de ser un remanso cultural que pasivamente recibió influencias indias, el sudeste Asiático jugó una parte constitutiva de la "Cosmópolis Sánscrita", y desempeñó un papel importante en Asia como una encrucijada y término de contactos budistas desde los primeros siglos de esta era.

Sobre la base de sus estudios epigráficos, Arlo Griffiths (2014a) subraya "el carácter panasiático del budismo y el lugar integral que el archipiélago indonesio desempeñó en el antiguo mundo budista".

Peter Skilling (2015) señala que «los mundos peninsular e insular de los mares del sur comparten una amplia cultura de rituales e ideas que se extendía desde Asia central a Asia oriental, y reevalúa la importante participación de Siam en un mundo mucho más amplio de intercambio cultural budista de lo que se suele suponer en la actualidad, cuestionando "si la India siempre debe ser el centro y Siam la periferia un receptor pasivo de la influencia-» (Skilling ,2009).

Hiram Woodward (2004) ha propuesto un argumento para "tratar a Indonesia y la India como una unidad integral hasta bien entrado el siglo IX, haciendo un caso de posible influencia del budismo Borobudur sobre los sucesivos acontecimientos en la India".

Según él, el monumento podría representar una fase del sistema cakra, que podría preceder a los textos budistas sánscritos existentes como el 
Sarvabuddhasamāyogạ̣ākinījālasamivara y el Hevajratantra (Woodward, 2009). Además, Woodward (1990) se abre a la posibilidad de que la invocación de Bhadracarī-pranidhāna -el texto representado en la serie más alta de relieves en Borobudur- sobre la memorial stūpa encontrada en el monasterio Nālandā establecido por Bālaputra podría representar un nuevo estímulo introducido por el monarca de Sumatra, o en cualquier caso la existencia de similitudes de larga data en la práctica religiosa en las dos áreas.

En todo caso, la fuerza creativa y constitutiva de los agentes y los medios del sudeste asiático en la transferencia, transformación y translocación de personas, textos, nociones y artefactos sigue sin apreciarse plenamente.

Piensen, por ejemplo, en la afirmación de Tāranātha de que, desde la época del rey Dharmapāla -finales del siglo VIII-principios del siglo IX-, había en madhyadeśa muchos estudiantes de los reinos del sudeste asiático y que durante el tiempo de los cuatro Senas aproximadamente la mitad de los monjes de Magadha eran del sudeste de Asia (Chattopadhyaya, 1982).

La contribución de los maestros insulares del sudeste asiático al budismo Vajrayāna en el Tíbet, también a través del puñado de textos compuestos en Suvarnadvīpa introducidos en el canon tibetano, es reconocida por la tradición tibetana del siglo XI y confirmada por la erudición moderna.

Se dice que el famoso maestro Atīśa (a.k.a. Dīpanikaraśrījñāna, 9801054), originario de Bengala, transmitió al Tibet el Durbodhāloka -un comentario sánscrito sobre el Abhisamayālañkāra-, compuesto en el sudeste asiático por su maestro Dharmakìrti de Suvarnadvīpa bajo el rey Cūḍāmanivarman -quien alrededor de 1019 d. C. fundó un templo 
budista en Nāgapatținam- (Skilling, 1997, 2007). Este suvarnadvīpī Dharmakìrti pudo haber sido el maestro que impartió a Atīśa las enseñanzas del Kālacakratantra, y ha sido identificado por Van der Kuijp (2003) como el autor del Netravibhanga, un comentario del Hevajratantra. Del siglo XI al XII, las tierras jemeres y Sumatra parecen haber sido los principales centros del culto de Hevajra, que pudo haber influido en los acontecimientos del sur de Asia.

Ambos Atisśa y Dharmakìrti eran fervientes devotos de Tārā, cuyo culto estaba extendido en el sudeste asiático insular, y que pudo haber sido popularizado en el Tíbet por Atīśa después de su estancia en Suvarnadvipa (Schoterman, 2016).

Wilkinson (1991) presenta pruebas de una conexión entre el culto de Gaṇeśa en el Tíbet y suvarnadvīpi Dharmakìrti. La transmisión de las ideas budistas de Sumatra y / o Java a la región del Himalaya se ha sugerido sobre la base de similitudes artísticas y arquitectónicas entre el monasterio de Tabo en Himachal Pradesh, que Atīśa visitó en 1042, y Borobudur (Wayman, 1981) (Nihom, 1994) (Kimmet, 2012) (Lokesh Chandra y Singhal, 1999).

Sea como fuere, es dificil no concordar con Skilling (1997) en que "la composición de Durbodhāloka presupone la existencia y estudio en Śrīvijaya de la literatura abstrusa Prajñāpāramitā y Abhisamayālaṃkāra; de un alto nivel de erudición y patrocinio realı.

Este escenario también es sugerido por la figura de Shihu (施 護, Dānapāla, 1018), un excepcionalmente prolífico monje traductor del sur de Asia que a finales del siglo X llegó a China con un buen conocimiento de los idiomas de Sanfochi -Śrivijaya- y Shepo -Java- (Sen, 2003) (Orzech, 2011a). 


\subsubsection{Nusantara}

Varios centros de culto budista en Nusantara -la región correspondiente al estado archipelágico moderno de Indonesia- son ahora considerados como bastiones del budismo esotérico desde el siglo VII al siglo XV y más allá. Este es el caso, por ejemplo, de Sumatra -es decir, los sitios del río Batang Hari, Padang Lawas y Muaro Jambi-; los complejos javaneses centrales de Borobudur, Candi Sewu, Plaosan, Mendut y Ratu Boko; los templos reales de los reinos Keḍiri, Sinhasāri y Majapahit en Java Oriental; y la isla de Bali, donde las comunidades de budistas tántricos han sobrevivido hasta el presente.

La existencia de una réplica del complejo monástico cingalés de Abhayagiri en Java Central, un monasterio de Śailendra-Śrivijaya en Nālandā y un Śailendra-Cūdāmanivarmavihāra en Nākappatținam; la supervivencia, además de los informes chinos, del sánscrito y de los materiales verbales vernáculos -tanto de fuentes epigráficas como manuscritas- de la tradición Mantranaya y Vajrayāna, algunos de los cuales contienen citas que se remontan a los tantras sánscritos; y los significativos restos de estatuas, utensilios rituales y monumentos, evocan el papel de Nusantara como sede reconocida de los cultos esotéricos en una cosmópolis budista altamente interconectada en lugar de una periferia remota y atrasada.

La evidencia multifacética, incluyendo el carácter arcaico, presistematizado del budismo tántrico de los siglos VIII y IX en Java y Sumatra, sugiere que los primeros desarrollos esotéricos que estaban surgiendo del Deccan occidental rápidamente llegaron al sudeste de Asia y fueron la base de las configuraciones religiosas posteriores.

La inscripción de Talang Tuo de la antigua malaya en Sumatra, que contiene la palabra vajraśarira, ha sido interpretada como un documento 
temprano del budismo Mantranaya (Woodward, 2004) (Kandahjaya, 2016). La evidencia epigráfica, junto con el relato del monje chino Yijing, que visitó Sumatra en el siglo VII, y el manual sánscrito-javanés Sañ Hyan் Kamahāyānikan, parecen arrojar nueva luz sobre la génesis del budismo esotérico a lo largo de la Cosmópolis budista, sugiriendo que el desarrollo de las enseñanzas esotéricas podría haber ocurrido antes de lo que se ha supuesto hasta ahora (Kandahjaya, 2016).

La evidencia histórica y textual del arte apunta a la existencia de vínculos budistas cercanos entre la India Occidental, la península malaya y Java en el siglo VIII.

Los ocho Bodhisattvas del siglo VIII de las cuevas de Ellorā (Malandra, 1993), Ratnagiri (Reichle, 2016) y la península malaya, donde forman parte de un maṇala dispuesto alrededor de una rueda girando Śākyamuni-Vairocana, se representan en las paredes exteriores de Candi Mendut y en el interior de Candi Plaosan.

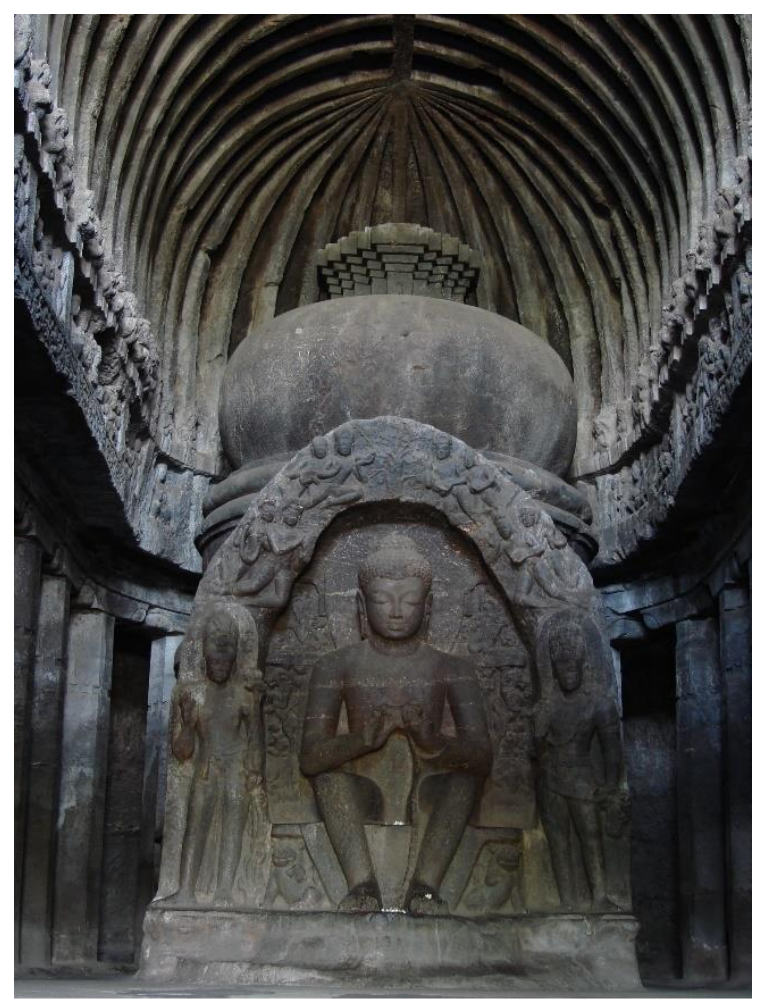

Buda en la Cueva 10, Ellora. Wikimedia Commons

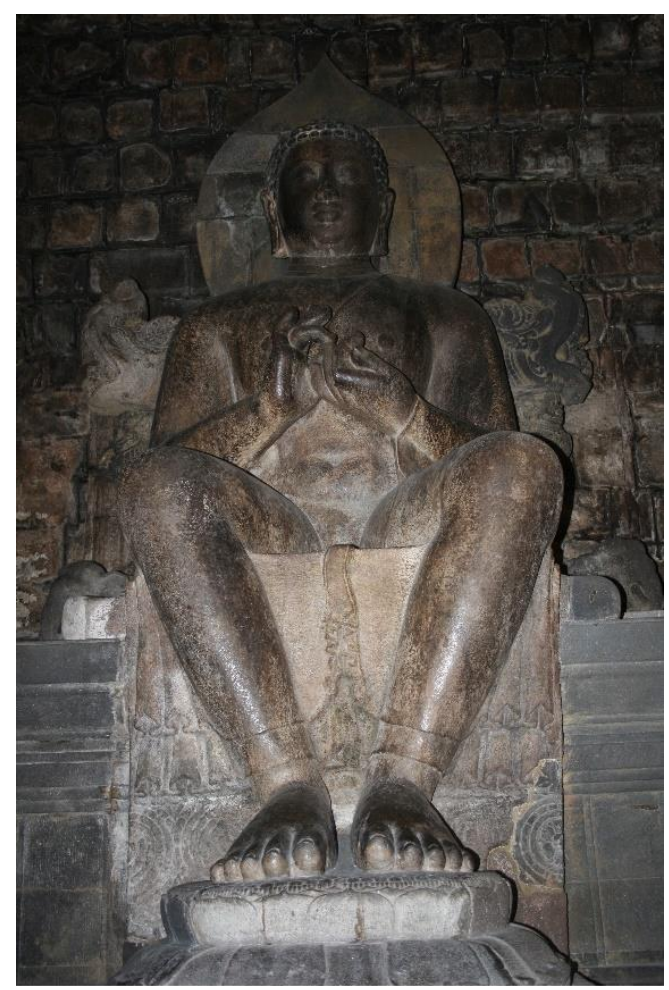

Buda central en Candi Mendut. CAndrea Acri 
Significativamente, esta formación mandalica se describe en el "prototántrico" Mạ̣dalāstasūtra, traducido al chino por Amoghavajra y, un siglo antes, por Punyyodaya. El antiguo monje viajó a China a través de Java, y este último fue activo en Camboya (Woodward, 2004) (Lin, 1935). Bautze-Picron (1997) detecta ecos entre la iconografia de los Ocho Bodhisattvas en Java, el budismo Shingon y las traducciones chinas del siglo VIII. Una posible influencia iconográfica derivada de Ellorā sobre el tríptico esculpido de Mendut ha sido planteada por Revire (2015a).

Tanto Sumatra como Java, probablemente, han actuado como lugares importantes en el desarrollo de las costumbres esotéricas de los cultos de Mañjuśrī y Tārā, que tenían un aspecto inherente marítimo en tanto que eran divinidades tutelares de los viajeros y especialmente de los marinos (Bopearachchi, 2014) (Ray, 2012).

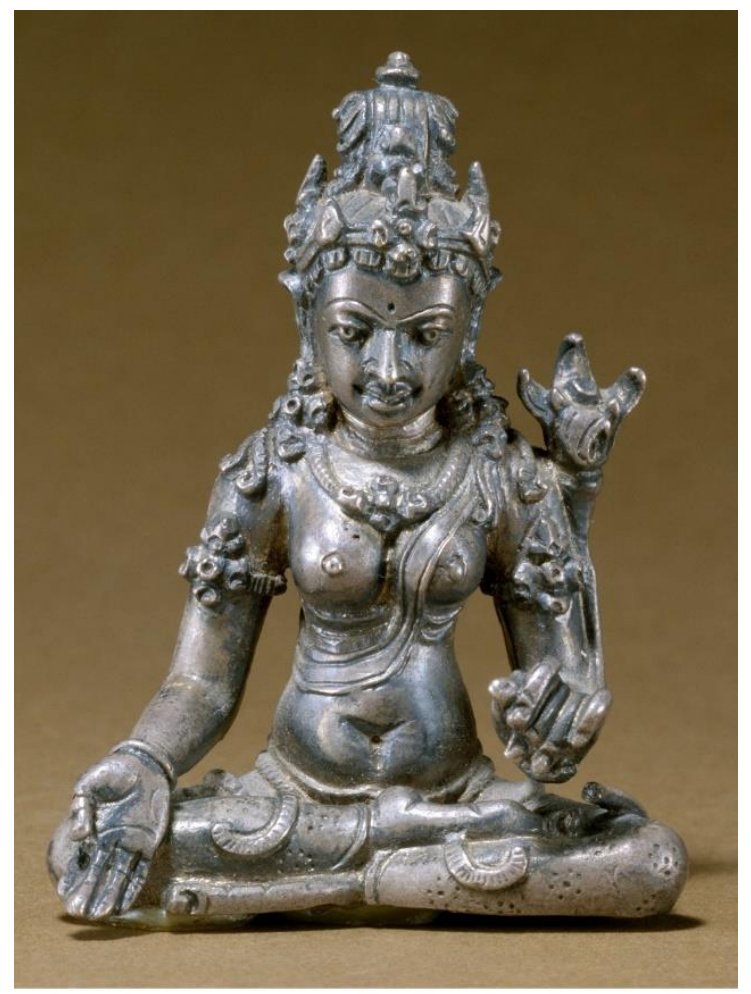

Tārā de plata, Java (s. IX al X); Colección Samuel Eilenberg, Acc. No. 1987.142.12. Foto cortesía del Museo Metropolitano (www.metmuseum.org)

La popularidad de esas deidades en Sri Lanka, el sudeste asiático, Java, Sumatra y China sugiere la existencia de fuertes conexiones 
budistas entre esas localidades en el siglo IX.18 Cruijsen, Griffiths y Klokke (2012) y Mevissen (1999) han analizado la evidencia sobre el culto panasiático de Mahāpratisarā -una deidad femenina relacionada con Tārā-y especialmente los testimonios javaneses sobre esas evidencias.

Según Mevissen, las dos regiones donde el culto de Mahāpratisarā era aparentemente popular entre los siglos VIII y X, es decir, el centro del imperio Tang en China -Dunhuang y Changan- y Java Central, están vinculados por las actividades de Amoghavajra, que tradujeron el Mahāpratisarādhārañi, y lo recitaron para evitar el naufragio mientras viajaban a China por mar (Chou, 1945) (Sundberg y Giebel, 2011).19

Java bajo los Śailendras, con monumentos budistas tan majestuosos y exquisitamente elaborados como Borobudur, Candi Sewu, Plaosan y Mendut, debe haber sido clasificado entre los grandes centros sagrados del budismo en ese momento. Esto puede inferirse, por ejemplo, de la inscripción en Siddhamātrkā de mediados del siglo IX desenterrada en Candi Plaosan en el área de Prambanan (Casparis, 1956), que describe la adoración en un templo de Buda -jinamandira- por peregrinos que llegaban continuamente desde Gurjaradeśa -Quizá Gujarat, o los dominios de los Gurjara-Pratihāras en el norte de la India-.

\footnotetext{
18 En Java y Sumatra como asientos tempranos de los cultos Mañjuśrī y Tārā, así como la posible conexión entre las formas de Tārā, los javaneses Nyai Loro Kidul y los chinos Guanyin, ver respectivamente Miksic 2006 y Jordaan 1997, 1998.

19 Sundberg (2004: 114-116) plantea la hipótesis de la presencia en Java de personalidades budistas chinas sobre la base de un dintel de Candi Sewu, que representa entre muchas figuras barbudas una apariencia distintiva sinitica. Woodward (1977) ha discutido algunos patrones de seda china sobre los motivos decorativos de Candi Sewu, especuló acerca de una influencia taoísta en los patrones numerológicos de las terrazas superiores de Borobudur (1999), y argumentó que el javanés Bianhong, que estudió en China bajo Huiguo, ha sido el "cerebro" de Borobudur (2009).
} 


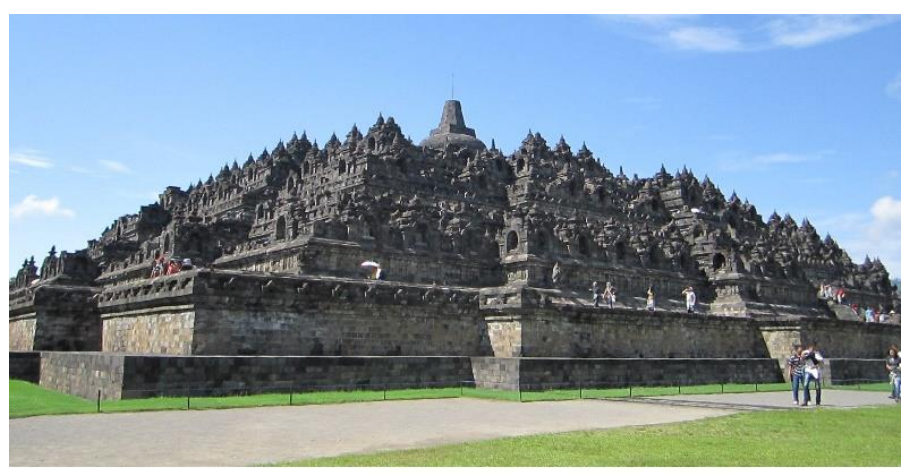

Borobudur, Java Central. (22Kartika, Wikimedia Commons

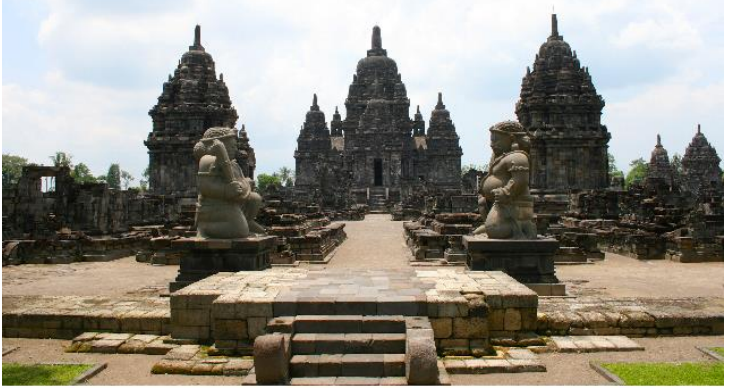

Candi Sewu, Java Central. CAndrea Acri

El manuscrito ilustrado del Așțasāhasrikā-Prajñāpāramitā CUL Add. 1643 dedica una viñeta a una imagen del Buda Dīpañkara en Java. Como argumentó Sinclair (2016) sobre la base de la geografia tántrica expuesta por el Manjuśriyamūlakalpa (51.636-640), "a finales del siglo VIII, a Kalingoḍra, el "Kəlin maritimo", se le había otorgado el reconocimiento de Buddhavacana en el mundo sánscrito".

Según un relato de Yuanzhao, compilado en el Zhenyuan Xinding Shijiao Mulu y también del maestro japonés Kūkai, Vajrabodhi conoció por primera vez a Amoghavajra en Java, quién seguramente mostró pruebas de sofisticación teológica (Chou, 1945) (Sundberg y Giebel, 2011).

Los vestigios del budismo Vajrayāna en Java de los siglos X y XI se pueden encontrar en los grupos de bronce de Surocolo y Nganjuk, que han sido utilizados para representar mandialas esotéricos dominados por Vajrasattva -la deidad central de las fases dos y tres del Budismo Esotérico-.20 Dado que la representación de este panteón en pinturas o estatuaria es relativamente escasa en el mundo budista, la acumulación de Surocolo es especialmente significativa (Szántó y Griffiths, 2015).

Sumatra acogió centros de renombre de la actividad budista y el aprendizaje superior en el siglo VII, como documentó Yijing, que elogió el

\footnotetext{
${ }^{20}$ Véase Lokesh Chandra y Singhal 1995; Tanaka 2010: 339; Sharma 2011. Sobre la popularidad de Vajrasattva como Ādibuddha tanto en Java como en Camboya, ver Sharrock 2006, 2007, 2011a; Cf. Conti 2014: 273-77 y Estève y Vincent 2010.
} 
alto nivel de las escuelas budista que encontró en Sumatra, donde se detuvo de Guangzhou a Nālandā y de allí de vuelta a China para leer Sūtras sánscritos.

Yijing informa que Śākyakìrti, uno de los cinco maestros budistas más distinguidos de su época, viajó a lo largo y ancho a través de las "Cinco Indias" y finalmente se estableció en Śrīijaya-Śrībhoja-.

A pesar de esta evidencia temprana, los restos arqueológicos y escasos documentos epigráficos, repartidos en lugares dispares de la isla especialmente a lo largo del río Batang Hari por ejemplo Muara Jambi y Muara Takus- han producido restos de monumentos e inscripciones budistas que en su mayoria datan de del siglo X al XIII y que muestran rasgos tántricos. ${ }^{21}$

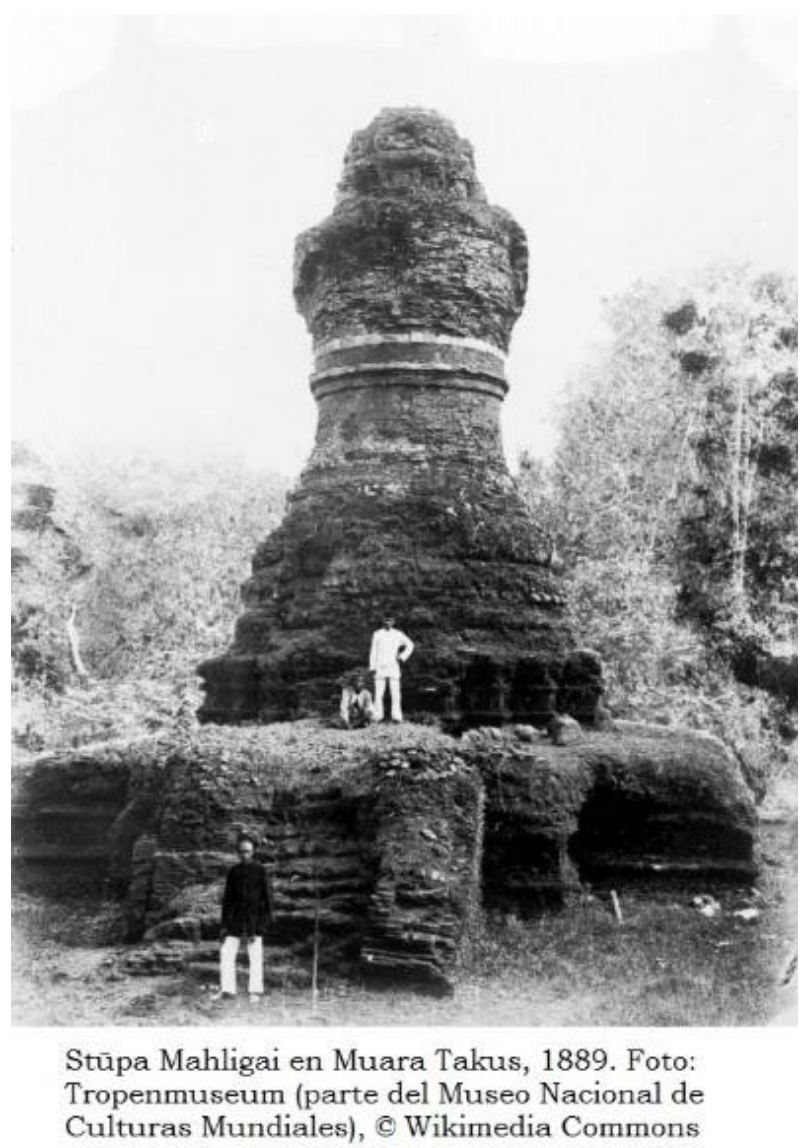

${ }^{21}$ Véase Woodward 2004; Reichle 2007; Griffiths 2014c; Miksic 2016; Kandahjaya 2016. 
El carácter salvaje y feroz de la iconografia esotérica budista y tántrica Shivaita que se desarrolló en las cortes de Kadiri-Sinhasāri y Majapahit del este de Java comparte rasgos con el de Sumatra, como lo atestiguan Biaro Bahal y Muara Takus, y la estatua Mahākāla atribuida al $\bar{A}$ dityavarman del siglo XIV.

Como lo sugiere Bautze-Picron (2014), las imágenes encontradas en los sitios Sumatra de Padang Lawas están integradas en una red que las conecta a Java oriental, Asia meridional, Camboya y Campā en los siglos XI y XIII.

En general, los sitios muestran una especie de budismo que pertenece a la misma fase de Vajrayāna como el que estaba presente en los dominios jemer y cham entre los siglos XII y XIII y en Java oriental y China en el siglo XIII. El Hevajratantra parece haber gozado de cierta popularidad en Sumatra y Suvarnadvipa es mencionado por este texto (Schoterman, 2016).

Además de la evidencia circunstancial mencionada anteriormente atribuyendo a Dharmakìrti, de Suvarnadvīpa, la autoría de un comentario al Hevajra debe considerarse la evidencia epigráfica presentada por Griffiths (2014c), sobre la inscripción de Saruaso II, que alaba al príncipe heredero Ananggavarman, hijo de Ādityavarman, cuya última línea menciona su "meditación diaria sobre Hevajra-nityāsmrtiḥ».

Por lo tanto, parece que Ādityavarman seguía la misma ideología y tecnología ritual, adoptada anteriormente por Kublai Kan y Krtanagara, que se equiparaba a la deidad central de los mandalas de los tantras budistas como el Guhyasamāja o el Hevajra. (Kozok, 2015) (BautzePicron, 2014). 


\subsubsection{La peninsula malaya}

Dada su ubicación geográfica estratégica, la península malaya, donde se ubicaban los dominios budistas Śailendra / Śrīvijaya, actuaba como una importante intersección en el tráfico de peregrinos que navegan por las rutas maritimas.

Testimonio a este hecho son las muchas tabletas votivas encontradas en múltiples sitios en el período del siglo VI al XII. Algunos de estos objetos muestran la iconografia Mahāyāna esotérica -por ejemplo, los ocho bodhisattvas mencionados anteriormente- y están grabados en manuscritos indios del noreste, sugiriendo que podrian haber pertenecido a peregrinos del subcontinente (Jacq-Hergoualc'h, 2002).

Los exquisitos Avalokiteśvaras de bronce de finales del siglo VIII que se encuentran en el distrito Chaiya de Tailandia moderna y en Bidor Perak, Malasia, muestran estrechas similitudes con los Avalokiteśvara encontrados en Wonogiri en Java Central (Fontein, 1990). Este hecho sugiere un vínculo entre la peninsula malaya y Java bajo la dinastía Śailendra, tal vez iniciado por el maestro Vajrabodhi mismo (Sharrock, 2012 y 2013a) (Guy, 2014) (Sharrock y Bunker, 2016).

El manuscrito de 1015 d. C. CUL Add. 1643 menciona un Lokanātha en el Monte Valavatī en Kedah -Kațahadvīpa- (Kim, 2014). Curiosamente, otro manuscrito de Aștasāhasrikā Prajñāpāramitā, pero que data de 1071 d. C., no contiene ninguna referencia a Kedah ni a Śrivijaya, lo que sugiere que ese modelo político perdió su posición prominente en el mundo budista, tal vez debilitado por las incursiones Cōla (Schoterman, 2016). 


\subsubsection{Los dominios jemer y cham}

Como lo atestiguan evidencias epigráficas y arqueológicas, los dominios cham y jemer se integraron plenamente en la conexion de redes intrarregionales del sudeste asiático que conectan el continente y la península malaya a Java, Sumatra y China entre los siglos VII y X.

Una inscripción del reinado de Jayavarman V (r 968-1000) nos dice que Kìrtipanditita, un adepto de los yogatantras budistas, actuó en capacidad de guru real, enseñando el Tattvasangraha y sus comentarios (Sanderson, 2004) (Green, 2014). El maestro budista esotérico Punyodaya viajó de la India a China y luego regresó a Asia continental (Lin, 1935) (Woodward, 1988, 2004).

Varias características iconográficas de Wat Phra Maen en Nakhon Pathom, así como la estatuaria budista relacionada de Dvāravatī, exhiben los iconos esotéricos, sugiriendo que las formas esotéricas del budismo de Mahāyāna pudieron haber evolucionado allí en el disfraz de Theravāda. Un fino khakkhara y varios otros objetos rituales de bronce tienen estrechos paralelos con material budista esotérico que se encuentra en Java central y más allá (Revire, 2009, 2015b).

Las instituciones monásticas y los templos consagrados a Lokeśvaras mahayanicos esotéricos se encuentran en los dominios cham y jemer en el siglo IX. Un pilar en la aldea An Thái, en la provincia de Quảng Nam de Vietnam, fechada en el 902 d.C., documenta un monasterio construido principalmente como un sitio de adoración Mahāyāna y Vajrayāna, donde Lokanātha es central para la función religiosa del vihāra.

Sanderson (2009) discute algunas inscripciones de los siglos IX y X que registran la instalación de los Lokeśvaras esotéricos -y, al mismo tiempo, deidades Śaiva- junto con la construcción y el apoyo de vihāras asociados, a saber, el pilar Đông Dương de 875 d. C. y el pilar Nham Biền 
de 908 d. C. Esta última inscripción relata que el cortesano Rājadvāra realizó dos viajes -siddhayātra, ya sea peregrinaciones o misiones diplomáticas- a Java (Green, 2014).

Otro vínculo con Java ha sido planteado por Chutiwongs (2005), que ve una conexión entre los elementos doctrinales que figuran en la inscripcion de An Thái y el Manual Budista Esotérico en sánscritojavanes antiguo "San் Hyan் Kamahāyānikan".

Woodward (2011) discute una relación entre la iconografia de Đông Dương y su relación con el "proto-tántrico" Käraṇdavyūha sūtra, un texto que informa la iconografia de Borobudur en Java. El mismo erudito (2004) menciona un pilar jemer del siglo X, también relacionado con el Kāraṇ̣avyūha, que lleva en una cara la figura de un Avalokiteśvara de ocho brazos -un icono que también aparece en la pared exterior trasera de Candi Mendut en Java Central.

Un nuevo enfoque en el budismo esotérico, sin duda provocado por el patrocinio real, se puede detectar entre los siglos X y XII en las formas de gobierno de la parte continental del sudeste asiático, incluidos los dominios de los chams a lo largo de los litorales vietnamitas.

Chutiwongs (2006) discute información sobre la construcción de un santuario a Heruka en Campā por Śrī Sūryavarmadeva hacia finales del siglo XII, durante la ocupación jemer. Los santuarios de Phimai y Si Thep, así como varios templos construidos en Angkor bajo el reinado de Jayavarman VII -como el Bayon y Banteay Chhmar- dan fe de los programas iconográficos tántricos, al igual que las numerosas estatuas de bronce desenterradas en la región. ${ }^{22}$

La divinidad iracunda Hevajra y la imagen de Heruka están representadas en varios bronces jemereses (Lobo, 1994), tal vez usados

${ }^{22}$ Véase Conti 2014; Woodward 1981; Sharrock 2006, 2007, 2009, 2011a , 2012, 2013a 2013 $^{\text {b }}$ 
como objetos de culto, en Banteay Chhmar y otros santuarios (Sharrock, 2006, 2013 ${ }^{\text {) }}$ (Conti, 2014) (Green, 2013), mientras que las yoginīs tántricas se destacan el los templos de Bayón y Phimai (Sharrock, 2013르).

La inscripción de Sab Bāk 1067 d. C., recuperada cerca de Nakhon Ratchasima, exhibe un carácter marcadamente Vajrayāna (Prapandvidya, 1990) (Sinclair, 2012) (Conti, 2014). Además de mencionar al Guhyasamāja y traicionar el conocimiento de ese sistema, la inscripción se hace eco de un "versículo distintivo" de Vāgīśvarakīrti, un exegeta del Guhyasamāja que proliferó en el este de la India a principios del siglo XI. Szántó sostiene que Vāgīśvarakìrti podría haber sido el paramaguru -gurú del guru- de Vrah Dhanus, el autor del versículo.

\subsubsection{Filipinas}

La erudición reciente ha reevaluado la herencia pre-cristiana, Indica de lo que ahora se llaman las islas filipinas. A pesar de las evidencias cuantitativamente escasas, hallazgos arqueológicos e inscripciones sugieren que el archipiélago integralmente pertenecía a las redes de Asia maritima budista.

Butuan en Mindanao era una vez una de las fuentes principales para el oro en la región, y podría haber sido visitada regularmente por las naves que transitaban la ruta de Java-China, como se evidencia por la presencia de mercancías Tang del siglo IX y -lo que es mas importantela estatuaria y atrefactos budista así como documentos epigráficos (Orlina, 2012). Estas incluyen una pastilla de Avalokiteśvara de arcilla de Luzón (Francisco, 1963a , 1971) y una inscripción de la región de Agusan en Mindanao que contiene una variante de un mantra contenido en Mahāpratisarāmahāvidyārājñ̄i (Orlina, 2012), lo que sugiere que el 
culto de Mahāpratisarā podría haber llegado a Filipinas desde Java poco después de las misiones de Amoghavajra (Op. Cit.).

Un artefacto notable es la estatuilla de oro de la diosa Vajralāsyā Bodhisattva de la danza amorosa- de la región de Agusan. Este icono tiene semejanzas estilísticas e iconográficas con el grupo de estatuas de bronce de Nganjuk en Java oriental y probablemente data de los siglos IX-X.23

Puesto que Vajralāsyā es una de las cuatro deidades asociadas con ofrecer ofrendas al Buda Vairocana y localizadas en la esquina sureste del Vajradhātumaṇdala (Capistrano-Baker, 2011), se puede argumentar que este manḍala, en su disposición tridimensional, era conocido en las Filipinas en el X siglo.

Los hallazgos de utensilios rituales budistas esotéricos y estatuarios originarios de Tausug se conservan actualmente en Butuan, en Mindanao, y esperan más estudio. ${ }^{24}$ Estos incluyen un doble vajra de bronce, una campana ritual, un slitdrum ${ }^{25}$ y un conjunto de imágenes de bronce de deidades femeninas y masculinas.

Los objetos más interesantes son una estatuilla que posiblemente representa una forma de Trailokyavijaya con seis brazos y una cabeza. Esta deidad, sin duda iconográficamente no estandar, pisotea los cuerpos entrelazados de Śiva y Umā -Shiva y Parvati o Shakti- con el rasgo característico de Trailokyavijaya -es decir no hace el esencial Vajrahūṃkāra mudrā delante de su pecho-, y dos estatuas de oro de deidades femeninas-posiblemente Tārā y Vajralāsyā -u otra deidad femenina relacionada con Vajradhātu-. Esta evidencia acumulativa

\footnotetext{
23 Esta estatuilla fue previamente identificada erróneamente como un Tārā estilísticamente atípica (véase Bronson 1975: 5). Cf. Francisco 1963b.

24 Estoy agradecido a Nicole Revel por haberme proporcionado sus fotografias de los artefactos en cuestión.

25 Estos son comparables a los ejemplares similares de javaneses orientales reproducidos y descritos en Griffiths y Lunsingh Scheurleer 2014.
} 
fortalece la impresión de que las Filipinas deben estar correctamente ubicadas en el mapa del budismo tántrico esotérico panasiático.

\section{Las redes maritimas del budismo esotérico}

La erudición reciente ha revelado las conexiones multidireccionales existentes entre los centros budistas, unidos entre sí por la superposición de redes de relaciones tanto religiosas como económicas, diplomáticas y políticas.

Por ejemplo, Tansen Sen (2003) ha explorado la intersección entre el comercio, la diplomacia y las redes budistas -emergentes, prototántricas- en el siglo VII y su integración en el mundo budista asiático en el siglo VIII.

Hall (2010) ha discutido las redes de comercio inter regionales del sudeste de Asia del siglo IX-X a la luz de las pruebas arqueológicas de los naufragios y la epigrafia. Y Sundberg y Giebel (2011) han explorado las redes diplomáticas y religiosas en la India, Sri Lanka, Java y China que fueron seguidas por los monjes budistas tántricos esotéricos Vajrabodhi y Amoghavajra.

Muchos de los residentes del sudeste y del este asiático recibieron el budismo a través de contactos diplomáticos y comerciales de alto perfil que llegaban a los entrepôts de Asia del sur y que se duplicaron como centros de difusión budista.

Esos cruces estratégicos del poder mercantil y político constituían los "nodos" que probablemente desempeñaron un papel crucial en la génesis y desarrollo del budismo en general y de las tradiciones tántricas en particular, en tanto que estos poderes mercantiles y politicos apoyaban prestigiosos centros de aprendizaje, patrocinaban congregaciones e 
instituciones monásticas que albergaban reliquias antiguas visitadas por peregrinos procedentes de todo el mundo indio.

Para entender el establecimiento -e interrupción- de esas redes, que fueron influenciadas por factores sociopolíticos, económicos y quizás incluso ambientales, se requiere un enfoque ecléctico.

Por lo tanto, para comprender mejor este fenómeno trans-regional multifacético como los patrones de transmisión budista en Asia maritima, se puede tratar de aplicar, como lo hizo Jason Neelis (2011) con respecto a Asia meridional, central y oriental, un "enfoque de redes" o un "modelo de redes".

Este enfoque individualiza los "nudos", los "conductos" y los "centros" que facilitan los procesos dinámicos de intercambio, yendo así más allá de las metáforas de los "flujos" culturales y las "influencias" que hasta ahora han caracterizado el discurso académico.

Las redes de clérigos budistas adheridas a nuevos desarrollos tántricos comenzaron a surgir a finales del siglo VII en lugares dispares, moviéndose a lo largo de las rutas maritimas que conectan el sur, el este y el sudeste de Asia. Ganando impulso en el siglo VIII, en lo que podría ser descrito como un "giro tántrico", el budismo tántrico esotérico se convirtió en un fenómeno casi panasiático.

Su expansión fue impulsada inicialmente por un puñado de maestros excepcionales dotados de una visión notablemente cosmopolita y de ambiciones internacionales, que cruzaban océanos y tierras en busca de conocimiento esotérico, escasas escrituras sánscritas, reliquias e iconos, hechizos poderosos y rituales de iniciación mandalica-Abhisekaimpartida por ācāryas renombrados, así como patrocinadores políticos.

Mientras que los comerciantes han sido considerados como los propagadores originales del budismo en su etapa temprana, es decir 
como los agentes principales de la difusión del "Budismo marino" a través de Asia (Bopearachchi, 2014) (Dayalan, 2013), ${ }^{26}$ una opinión alternativa mira el desarrollo del budismo esotérico como un asunto eminentemente real (Davidson, 2002) (White, 2012).

Es dificil negar que tal vez el factor impulsor más importante para la expansión del budismo tántrico esotérico fue la relación entre sus especialistas rituales y las élites reales. Atraídos por la promesa de la invencibilidad, la protección del Estado y los poderes sobrehumanos, la realeza a menudo empleaba monjes tántricos como capellanes reales, siguiendo así el patrón que ya existía entre los purohitas brahmanes y las cortes a las que servian.

Los reyes que patrocinaron o concedieron el reconocimiento directo como religión estatal al budismo tántrico esotérico pertenecian a dinastias asiáticas prominentes y casi contemporáneas entre sí, como los primeros Candras (r. 850-1050) y Pālas (r. 750-1199) en el subcontinente indio del noreste, y los primeros Bhauma-Karas en Odisha (r. 825-950); la dinastía Yarlung en el Tíbet (r. 618-842); el segundo Lambakannas temprano en Sri Lanka -de finales del VII a mediados del IX siglo, hasta Sena I-; los Śailendras y los gobernantes de Śrīijayan afines en Java, Sumatra y la península malaya (siglos XVII-XIII); la dinastía Tang de China (r. 618-907), especialmente bajo el emperador Daizong (762-79); la posterior monarquía de Silla en Corea (r 661-935) y la dinastía imperial japonesa en el período de Heian (r. 794-1185).

Algunas de las figuras reales del siglo XI que abrazaron y patrocinaron el budismo esotérico fueron Jayavarman VII en Camboya (r. 1181-1220), Kṛtanagara en Java oriental (r 1268-92), Kublai Kan en China (r. 126094), y Ādityavarman en Sumatra (r. ¿?-1375). 
Robert Linrothe (1999) ha elaborado un modelo esquemático que abarca tres fases del budismo esotérico, sobre la base de los desarrollos iconográficos y doctrinarios de cada uno de ellos. Si bien señala que algunas de las etapas posteriores al siglo VIII pueden ser contemporáneas y contiguas, argumenta que la fase uno domina el período comprendido entre finales de los siglos VI a VIII, la segunda fase preside desde el VIII hasta el siglo X y la fase tres desde finales del siglo X hasta el siglo XII (Op. Cit.: 13).

Aunque este modelo puede tener su utilidad al analizar los aspectos históricos o soteriológicos más amplios del budismo esotérico, aquí prefiero usar el término "ola" como metáfora para la extensión de las maneras esotéricas en Asia, e identificar dos ondas principales. La primera entre los siglo VII y X, la segunda de alrededor de finales del siglo $\mathrm{X}$ al XIII. Cada una de estas ondas parece haberse caracterizado por nuevas redes religiosas, configuraciones sociopolíticas, cánones bíblicos y modas iconográficas.

\subsection{La primera ola del budismo esotérico (del siglo VII a principios del siglo $X)$}

Las primeras redes que iniciaron la expansión panasiática de la "primera ola" de un paquete budista esotérico a partir del siglo VII fueron constituidas por monjes afiliados a órdenes esotéricas relacionadas que viajaron por los caminos abiertos por los comerciantes de larga distancia que favorecian el rápido intercambio de bienes, gente e ideas.

Gracias a la evidencia textual, y especialmente a las biografias chinojaponesas de los primeros maestros, ahora somos capaces de reconstruir, aunque con un elemento de incertidumbre, el probable círculo genealógico y social de esos prominentes agentes individuales. 
Esas personalidades carismáticas, más a menudo asociadas a una vigorosa actividad de traducción, de trabajo de comentarios y de iniciación de alumnos, viajaban a veces, trazando los pasos de sus maestros, hacia el este y hacia el oeste a lo largo de las rutas maritimas entre el subcontinente indio y Japón.

Es probable que esta red de maestros, muchos de los cuales están obligados a permanecer desconocidos para nosotros, y sus discípulos que adquirieron, transformaron y propagaron imágenes, textos y prácticas devocionales relacionadas con los Bodhisattvas Mañjuśrī y Vajrapāṇi y los dioses y diosas salvadores, tales como Avalokiteśvara, Tārā y Mahāpratisarā, que eran populares tanto en los entornos exotéricos Mahāyāna como esotéricos tántricos.

Entre los monjes prominentes tempranos están el Atikūta de India central (650) y Punyodaya (chino Nati 那 提, 650), el Yijing chino (635713),27 Baosiwei (寶 思惟, Skt. Maṇicinta-na / Mañicinta o Ratnacinta, (721), y del sur de la India Dharmaruci / Bodhiruci (727).

Los vectores e iniciadores de una forma sistemática y totalmente desarrollada de budismo esotérico son "tres grandes ācāryas" del período Tang medio, a saber, el indio Śubhākarasimha (ch. Shanwuwei 善 無畏, 637-735), ${ }^{28}$ Vajrabodhi (ch. Jingangzhi 金剛智, 671-741), ${ }^{29}$ y, el discípulo

\footnotetext{
${ }^{27}$ Aunque se discute el estado de Yijing como monje budista esotérico, sus biografias sugieren que él entrenó con Śubhākarasimha y conoció las enseñanzas de los Vajraśekhara y Guhyatantra, además de escribir un comentario del Mahāvairocanasūtra (ver Keyworth en Orzech, Sørensen y Payne 2011: 342 - 43, Shinohara 2014: 147 - 67).

28 Probablemente era el hijo mayor del rey Buddhakara, presunto antepasado de los reyes de la dinastía Bhauma-Kara de Odisha (Chou, 1945) (Orzech, Sørensen y Payne, 2011) (Tanaka, 2014). Otra teoría intrigante especula que él era heredero-aparente a Mādhavarāja II, es decir Mãdhyavarāja III, o "Yaśobhita II de la dinastía de Śailodbhava que gobernó Koṇgoḍa [es decir, Oḍra] durante el tercer cuarto del siglo VII "(Hodge, 2003).

29 Según un relato de Zanning, era un brahman del sur de la India (Malayakūta), cuyo padre servía como purohita en la corte real de Kāññi (Orzech, Sørensen y Payne, 2011b). Por el contrario, la biografia de Lü Xiang informa que él era el tercer hijo de Ísānavarman (yeshanawamo 伊舍那靺摩), el rey kșatriya de una dinastía del centro de la India (es decir, los Maukharis), y porque posteriormente fue recomendado al [chino] Emperador por Mizhunna (米准 那), el general del rey de un reino indio del sur, él acabó siendo llamado un indio del sur (Sundberg y Giebel, 2011).
} 
ordenado de Vajrabodhi, Amoghavajra (ch. Bukong 不 空, 704-74, probablemente nativo de Samarkanda). ${ }^{30}$

Esta tríada, que inspiró a varias generaciones de alumnos, debía estar asociada con un "canon", por así decirlo, de escrituras reveladas,

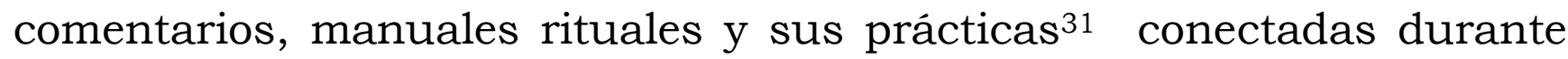
muchos siglos.

Entre las figuras de los siglos VIII y IX relacionadas con esta triada, y especialmente a su último miembro Amoghavajra, estaban Nāgabodhi (chino Longzhi 龍 智),32 cuya biografia sigue siendo oscura pero que se cree que conoció a Amoghavajra en Sri Lanka en los años 740 y antes a Vajrabodhi; los discípulos chinos de Amoghavajra Huilang (¿?-781) y Huiguo (745-806), discípulo javanés de este último Bianhong (辨 弘, finales del siglo VIII); Prajña (chino. Boruo 般若, alt. Bolaruo 般 剌 若, 744810, ya sea del actual Afganistán o del sur de la India), ${ }^{33}$ discípulo del alumno prominente de Amoghavajra, Yuanzhao (800); los coreanos Pulga Saui y Hyech'o (ambos del siglo VIII), ${ }^{34}$ discípulos de Śubhākarasimha y

\footnotetext{
30 Biografias chinas de Amoghavajra presentan información contradictoria, describiéndolo como el hijo de un Brahman o un comerciante de Asia Central. Chou (1945) argumenta que los biógrafos de Amoghavajra trataron de ocultar su embarazoso trasfondo como comerciante, lo cual sería indigno para un monje de su rango.

${ }^{31}$ Estos fueron los Mahãvairocanasūtra y Susiddhikaramahātantra (primero propagados por Śubhākarasimha), el Sarvatathāgatatattvasañgraha (propagado por Vajrabodhi), versiones de el Guhyasamāja (ya conocido por Nāgabodhi), Śrīparamādya, Sarvabuddha-samāyoga, otras escrituras reveladas pertenecientes al ciclo de Sarvatathāgata-tattvasangraha / Vajraśekhara (Jingangding 金剛 頂, resumido y propagado por Amoghavajra), así como Jingangding jingangding de Amoghavajra yuqie shibahui zhigui.

$32 \mathrm{El}$ material biográfico de esta figura, que se dice que ha vivido durante cien años y contado entre los Mahāsiddhas, es sobre todo de naturaleza sobrenatural o legendaria -por ejemplo, que fue instruido por el Mahāsiddha Nãgārjuna y, como éste, Residía en Śrīśailam o Kāñāī; Sin embargo, su historicidad no puede ser descontada automáticamente por esos motivos. En esta figura, cuyo nombre chino se traduce de diversas formas en fuentes secundarias como Nāgabodhi, Nāgabuddhi, o Nāgajñāna / Nāgajña, ver Sinclair 2016b.

33 Abe (1999) apoya -a mi juicio, con razón- la identificación de Prajña con el Prajñābodhi, nativo del sur de la India, mencionado por el monje chino Chih-Kuang (van Gulik, 1980). De acuerdo con este relato, Prajña (bodhi) llegó a la India a través de los Mares del Sur, trayendo consigo manuscritos de hoja de palma de dhāranīs.

34 En los extensos y aparentemente repetidos viajes de Hyech'o a India y Asia Central, ver Deeg 2010.
} 
ambos Vajrabodhi y Amoghavajra respectivamente); y el japonés Kūkai (774-835), discipulo de Huiguo y Prajña. ${ }^{35}$

Las redes de los monjes de los siglos VII-IX ofrecen un cuadro revelador del extraordinario período de conectividad intra-asiática que se convirtió en el sello distintivo del auge y la difusión de las tradiciones budistas esotéricas en el curso de sólo dos o tres generaciones.

\subsection{La segunda ola del budismo esotérico (de fines del siglo $\mathrm{X}$ al siglo XIII)}

El período comprendido entre mediados del siglo IX y finales del siglo $\mathrm{X}$ se ha caracterizado como una "era oscura para el budismo" en China y el Tíbet (Matsunaga, 1978), y también se observa una escala reducida de actividades de construcción budistas en el sudeste Asiático, con la única excepción del templo de Đông Dương en Campā (Woodward, 2011).

Esta situación puede haber estado relacionada con la interrupción de las redes diplomáticas, religiosas y comerciales entre las localidades donde el apoyo al budismo esotérico, o el budismo por completo, por las élites gobernantes se desvaneció, como en China bajo el emperador Wuzong (814-46) Tíbet bajo el rey Lang Darma (838-41), Sri Lanka bajo Sena II (854-89) y sus sucesores (Sundberg, 2014, 2016), y Java alrededor de 850 en adelante (Sundberg, 2016) (Acri, 2016 b).

Aparte de las contingencias sociopoliticas, tales cambios de paradigma pueden haber ocurrido como resultado de "reformas" religiosas que promovieron un giro hacia las variedades no-esotéricas de las tradiciones budistas -como sucedió, por ejemplo, en Sri Lanka y, en una fecha posterior, en Myanmar y Camboya con respecto a la prevalencia del

\footnotetext{
35 Para una lista de varios otros monjes indios que "vinieron a la Tang y se asentaron, enseñaron y tradujeron textos" en el curso del siglo IX, como Shi Mayue, Bodhivajra, Vajrasiddhi, Bodhirși y Prajñacakra, véase Orzech en Orzech, Sørensen y Payne 2011b: 328-30.
} 
budismo Theravāda / Pali sobre Mahāyāna y Vajrayāna- o incluso diferentes religiones como sucedió, por ejemplo, en Java Central.

Otro factor puede haber sido la contracción del imperio Pāla (850-977), lo que podría haber causado una disminución en las ventajas reales al budismo esotérico en el noreste de la India (Sanderson, 2009) y un efecto negativo en cascada en el exterior, especialmente con respecto al comercio marítimo.

El budismo esotérico recuperó su ímpetu en el siglo XI -la segunda olay permaneció vital durante los siglos XII y XIII en gran parte del Asia marítima. Las principales figuras reales de ese período que eligieron al budismo esotérico como su culto personal y oficial, o apoyaron los rituales tántricos como un medio para lograr sus fines politicos, son Jayavarman VII en Camboya (r. 1181-1220), Kṛtanagara en Java Oriental (r. 1268-92), y Kublai Kan en China (r. 1260-94).

Habiendo desaparecido prácticamente el budismo tántrico en el subcontinente indio a finales del siglo XIII, siguió viviendo e incluso prosperando en sus adaptaciones localizadas o formas protéicas como señala Gómez (2016), hasta el siglo XV en Java y Sumatra -por ejemplo bajo el rey Ādityavarman,- y el día de hoy en Nepal, Tỉbet, Bali y Japón.

Las imágenes de estilo nālandā de las divinidades budistas esotéricas reaparecen en Angkor de los siglos XI y XII, Pagan, península malaya y Java oriental (Skilling, 2007).

Los acontecimientos politicos internacionales desfavorables, y sobre todo el declive del budismo en el norte de la India, pudieron haber provocado el surgimiento de nuevas redes a fines del siglo XIII.

Nālandāy Vikramaśîla han sido arrasados, los eruditos y los artesanos huyeron a Nepal y al Tíbet (von Schroeder, 1981), y posiblemente más lejos al sudeste de Asia. 
Según Tāranātha, la mayoría de los eruditos budistas de madhyadeśa huyeron a la parte continental del sudeste asiático -es decir, los reinos de Pegu, Campā, Kamboja, etc.- después de que Magadha fue invadida por los turcos (Chattopadhyaya, 1980).

Filliozat (1969) y Sharrock (2007) han observado una influencia nepalí -newar- sobre la arquitectura jemer de ese período. Como lo señaló O'Brien (2016), existía una diáspora de artesanos newar en la esfera sinotibetana, y estos artesanos se hicieron populares en la corte de Kublai Kan en un momento que coincide con el reinado de Krtanagara, el adversario javanés de Kublai y el Patrón de Candi Jago. Hay registros de elementos nerwar o del nordeste de la India, en detalles decorativos y en estatuas de arte budista javanés del este (O'Brien, 1993).

Schoterman (1994) señaló que las cinco estatuas principales de Bodhisattvas en Candi Jago fueron ejecutadas de acuerdo con las enseñanzas del sánscrito Amoghapāśasādhana, que fue escrito por Śākyaśrībhadra en el norte de la India alrededor del año 1200 y puede haber llegado a Java poco después.

Lunsingh Scheurleer (2008) subraya la influencia india del noreste sobre una escultura de Java en el período Sinhasāri y también de Sumatra en el año 1286 por Kṛtanagara, que fue reconstituida alrededor de mediados del siglo XIV por Ādityavarman (Reichle, 2007).

Las estatuas budistas inscritas en Nāgarī de Candi Jago y la aparición de las palabras bharāla (dios) y bharālī (diosa) en una serie de inscripciones asociadas con Kṛtanagara, sostienen un posible vínculo con el noreste de la India y especialmente newar. ${ }^{36}$

\footnotetext{
36 Ver Lokesh Chandra 1983, Kandahjaya 2004: 68-69, Sinclair 2012 y Griffiths 2014c, que discuten la certificación de las palabras bharāla y bharālī y sus probables cognados bahāla, bahära y bharāda (bhatțāra [ka], como sugiere Lienhard 1999: 38) en fuentes newar.
} 


\section{Conclusión}

Mi artículo destaca la importancia de las rutas maritimas de la seda en la génesis, el desarrollo y la difusión del budismo esotérico en una gran parte de Asia. Describe las regiones litorales e insulares del sur y el sudeste asiático que acogieron importantes centros del budismo esotérico y se centra en las redes dinámicas e internacionales de agentes humanos que fueron instrumentales en la transmisión y transformación de los cultos, rituales, textos e imágenes del budismo esotérico.

Es digno de señalar que todas las figuras principales en la transmisión del budismo tántrico esotérico a China y al sudeste asiático hasta el siglo IX fueron monjes.

Sin embargo, una categoría no-monástica como los "practicantes no ordenados Vajrācāryas" parece haber llegado a ser más importante que los "monjes Vajrācārya" en el sur de Asia durante la fase tardía de Vajrayāna en el sur de Asia. Los balineses modernos "brhamanes budistas" y los nepaleses Vajrācāryas pueden ser considerados los herederos de esta categoria de practicantes laicos (Sinclair, 2012).

Un desiderátum académico actual sigue siendo identificar las redes de practicantes no institucionalizados, que incluyan siddhas y especialistas en rituales de castas bajas, que contribuyeron a la difusión de las formas del tantrismo en ultramar. 


\section{Referencias}

Abé, R., Weaving of Mantra: Kūkai and the Construction of Esoteric Buddhist Discourse, New York: Columbia University Press, 1999.

Abu-Lughod, J., Before European Hegemony: The World System A.D. 1250-1350, New York: Oxford University Press, 1989.

Acri, A., 'Introduction: Esoteric Buddhist Networks along the Maritime Silk Routes, 7th-13th Century ad', in A. Acri (ed.), Esoteric Buddhism in Mediaeval Maritime Asia: Networks of Masters, Texts, Icons, Singapore: ISEAS Publishing, 2016, pp. 1-26.

Acri, A., 'Once More on the "Ratu Boko Mantra": Magic, Realpolitik, and Bauddha-Śaiva Dynamics in Ancient Nusantara', in A. Acri (ed.), Esoteric Buddhism in Mediaeval Maritime Asia: Networks of Masters, Texts, Icons, Singapore: ISEAS Publishing, 2016b, pp. 323-48.

Ardika, I.W., 'Early contacts between India and Bali', in ASEAN-India Cultural Links: Historical and Contemporary Dimensions. Proceedings of the International Conference on "ASEANIndia Cultural Links: Contemporary and Historical Dimensions”, 23-24 July 2015, New Delhi, India, New Delhi: ASEAN-India Centre, Research and Information System for Developing Societies, 2015, pp. 27-37.

Bautze-Picron, C., 'Le Groupe des Huit Grands Bodhisattva en Inde: Genèse et Développement', in Eilenberg, N., et al. (eds.), Living a Life in accord with Dhamma: Papers in Honor of Professor Jean Boisselier on His Eightieth Birthday, Bangkok: Silpakorn University, 1997, pp. 1-55.

Bautze-Picron, C., 'Buddhist Images from Padang Lawas region and the South Asian connection', in D. Perret (ed.), History of Padang Lawas, North Sumatra; II: Societies of Padang Lawas (Mid-Ninth-Thirteenth century CE), Paris: Cahiers d'Archipel, 2014, pp. 107-28.

Bopearachchi, O., 'Sri Lanka and the maritime trade: the impact of the role of the Bodhisattva Avalokiteśvara as the protector of mariners', in P.P. Dhar and U. Singh, Asian Excavation: Networks of Cultural Interaction, New Delhi: Oxford University Press, 2014, pp. 161-87.

Brancaccio, P., The Buddhist Caves at Aurangabad: Transformations in Art and Religion, Leiden: Brill, 2010.

Bronson, B., 'Field Museum's Agusan Gold Image: The most spectacular find yet made in Philippine archeology', Field Museum Bulletin, vol. 46.7, no. 5, 1975.

Caldwell, I., and Hazlewood, A., The holy footprints of the venerable Gautama; A new translation of the Pasir Panjang inscription', Bijdragen tot de Taal-, Land- en Volkenkunde, vol. 150, 1994, pp. 457-80.

Capistrano-Baker, F.H., 'Butuan in early Southeast Asia', in: Capistrano-Baker (ed.), Philippine Ancestral Gold, Makati City: Ayala Foundation, 2011, pp. 191-257.

Casparis, J.G. de, Prasasti Indonesia I. Bandung: A.C. Nix \& Co, 1950. 
Casparis, J.G. de, Prasati Indonesia II: Selected inscriptions from the 7th to the 9th centuries AD, Bandung: Masa Baru, 1956.

Casparis, J.G. de, 'New evidence on cultural relations between Java and Ceylon in ancient times', Artibus Asiae, vol. 24, 1961, pp. 241-48.

Chandawimala, R., Buddhist Heterodoxy of Abhayagiri Sect. A Study of the School of Abhayagiri in Ancient Sri Lanka, Saarbrücken: Lambert Academic Publishing, 2013.

Chattopadhyaya, D. (ed.)., Tāranātha's History of Buddhism in India (translated from Tibetan by Lama Chimpa and A. Chattopadhyaya), Calcutta: K.P. Bagchi \& Company, 1980. [Reprint of 1970 edition, Shimla: Indian Institute of Advanced Study.]

Chou, Y.L., 'Tantrism in China', Harvard Journal of Asiatic Studies, vol. 8, no. 3-4, 1945, pp. 241332.

Chutiwongs, N., 'Le Bouddhisme du Champa', in Baptiste, P., and Zéphir, T. (eds.), Trésors d'art du Vietnam. La sculpture du Champa Ve-XVe siècles, Paris: Réunion des Musées Nationaux and Musée des Arts Asiatiques Guimet, 2005, pp. 65-87.

Chutiwongs, N., 'A Buddhist Bhairava', in B. Baumer et al. (eds.), Sahṛaya: Studies in Indian and South East Asian Art in Honour of Dr. R. Nagaswamy, Chennai: India Tamil Arts Academy, 2006, pp. 53-64.

Conti, P., 'Tantric Buddhism at Prasat Hin Phimai: A New Reading of its Iconographic Message', in N. Revire and S. Murphy (eds.), Before Siam; Essays in Art and Archaeology, Bangkok: River Books and The Siam Society, 2014, pp. 374-95.

Cruijsen, T., A. Griffiths, and M.J. Klokke, 'The cult of the Buddhist dhāranī deity Mahapratisara' along the Maritime Silk Route: new epigraphical and iconographic evidence from the Indonesian Archipelago', Journal of the International Association of Buddhist Studies, vol. 35, 2012, pp. 71-157.

Davidson, R.M., Indian Esoteric Buddhism: A Social History of the Tantric Movement, New York: Columbia University Press, 2002.

Dayalan, D., 'Role of Trade and Tamil Traders in Promoting Buddhism', in Dayalan, D. (ed.), Śivaśrī: Perspectives in Indian Archaeology, Art and Culture, New Delhi: Agam Kala Prakashan, 2013, pp. 15-31.

Decleer, H., "The Life of Buddha-Jñāna-pāda and his spiritual descendants for the Samāja and Yamāntaka transmissions in the "Nyö (Gnyos) lineage" thankga', Unpublished manuscript, n.d.

Deeg, M., 'Has Huichao Been Back to India? On a Chinese Inscription on the Back of a Pāla Bronze and the Chronology of Indian Esoteric Buddhism' in Franco, E., and Zin, M., (eds.), From Turfan to Ajanta: Festschrift for Dieter Schlingloff on the Occasion of his Eightieth Birthday, Kathmandu: Lumbini International Research Institute, 2010, pp. 197-213. 
Degroot, V., 'The archaeological remains of Ratu Boko: From Sri Lankan Buddhism to Hinduism', Indonesia and the Malay World, vol. 34, no. 98, 2006, pp. 55-74.

Dohanian, D., The Mahāyāna Buddhist Sculpture of Ceylon, New York: Garland House, 1977.

Donaldson, T., 'Probable Textual Resources for the Buddhist Sculptural Mandalas of Orissa', East and West, vol. 45, no. 1, 1995, pp. 173-204

Donaldson, T., Iconography of the Buddhist Sculpture of Orissa, New Delhi: Indira Gandhi National Centre for the Arts/Abhinav Publications, 2001.

Emigh, J., Masked Performance: The Play of Self and Other in Ritual and Theatre, Philadelphia: University of Pennsylvania Press, 1996.

Estève, J., and B., Vincent, 'L'about inscrit du musée national du Cambodge (K. 943): nouveaux éléments sur le bouddhisme tantrique à l'époque angkorienne', Arts Asiatiques, vol. 65, 2010, pp. 133-158.

Filliozat, J., 'Emigration of Indian Buddhists to Indo-China c. A.D. 1200', in Lal, K.S., (ed.), Studies in Asian History: proceedings of the Asian History Congress 1961, New Delhi: Asia Publishing House, 1969, pp. 45-48.

Fontein, J., 'The Sculpture of Indonesia', in Fontein, J. (ed.), The Sculpture of Indonesia, Washington: National Gallery of Art, 1990, pp. 113-300.

Francisco, J.R., 'A Buddhist image from Karitunan Site, Batangas Province' Asian Studies, vol. 1, 1963a, pp. 13-22.

Francisco, J.R., 'The golden image of Agusan: a new identification', Asian Studies, vol. 1, 1963b, pp. 31-39.

Francisco, J.R., 'A note on the golden image of Agusan', Philippine Studies, vol. 2, no. 3, 1963c, pp. 390-400.

Francisco, J.R., The Philippines and India: Essays in ancient cultural relations, Manila: National Book Store, 1971.

Gippert, J., 'A Glimpse into the Buddhist Past of the Maldives; I: An Early Prakrit Inscription', Wiener Zeitschrift für die Kunde Südasiens, vol. 48, 2004, pp. 81-109.

Gippert, J., 'Sanskrit as a Medium of Maldivian Buddhism', in L. Göhler (ed.), Indische Kultur im Kontext: Rituale, Texte und Ideen aus Indien und der Welt; Festschrift für Klaus Mylius, Wiesbaden: Harrassowitz, 2005, pp. 213-20.

Gómez, O. R. (2016). Antonio de Montserrat-La Ruta de la Seda y los caminos secretos del Tantra. Revista Científica Arbitrada de la Fundación MenteClaral Tantra, 1(1), 5-20. http:/ / fundacionmenteclara.org.ar/revista/index.php/RCA/article/view/8

Goris, R., Prasasti Bali: Inscripties vóór Anak Wungçu, 2 vols, Bandung: Masa Baru, 1954.

Green, P.S.E. ‘Two internal pediment scenes from Banteay Chhmar', Udaya, vol. 11, 2013, pp. 99139. 
Green, P.S.E., 'The Many Faces of Lokeśvara: Tantric Connections in Cambodia and Campā between the Tenth and Thirteenth Centuries', History of Religions, vol. 54, no. 1, 2014, pp. 69-93.

Griffiths, A., 'Imagine Lan்kapura at Prambanan', in A. Acri, H. Creese, and A. Griffiths (eds.), From Lan̉kā eastwards: The Rāmāyaṇa in the literature and visual arts of Indonesia, Leiden: KITLV Press, 2011a, pp. 133-48.

Griffiths, A., 'Inscriptions of Sumatra: Further data on the epigraphy of the Musi and Batang Hari rivers basins', Archipel, vol. 81, 2011b, pp. 139-75.

Griffiths, A., 'Inscriptions of Sumatra II: Short epigraphs in Old Javanese', Wacana, vol. 14, no. 2, 2012, pp. 197-214.

Griffiths, A., 'The Problem of the Ancient Name Java and the Role of Satyavarman in Southeast Asian International Relations Around the Turn of the Ninth Century CE', Archipel, vol. 85, 2013, pp. 43-81.

Griffiths, A., 'Written Traces of the Buddhist Past: Mantras and Dhāraṇīs in Indonesian Inscriptions', Bulletin of the School of Oriental and African Studies, vol. 77, 2014a, pp. 137-94.

Griffiths, A., "The "greatly ferocious" spell (Mahāraudra-nāma-hṛdaya): A dhāraṇī inscribed on a lead-bronze foil unearthed near Borobudur', in K. Tropper (ed.), Epigraphic Evidence in the Pre-Modern Buddhist World: Proceedings of the Eponymous Conference Held in Vienna, Vienna: Arbeitskreis für Tibetische und Buddhistische Studien, 2014b, pp. 1-36.

Griffiths, A., 'Inscriptions of Sumatra, III: The Padang Lawas Corpus studied along with inscriptions from Sorik Merapi (North Sumatra) and Maura Takus (Riau)', in D. Perret (ed.), History of Padang Lawas, North Sumatra. II: Societies of Padang Lawas (9th c.-13th c.), Paris: Association Archipel, 2014c, pp. 211-62.

Griffiths, A., and P. Lunsingh Scheurleer, 'Ancient Indonesian Ritual Utensils and their Inscriptions: Bells and Slitdrums', Artibus Asiae, vol. 69, 2014, pp. 129-150.

Griffiths, A., N. Revire and R. Sanyal, 'An Inscribed Bronze Sculpture of a Buddha in bhadrāsana at Museum Ranggawarsita in Semarang (Central Java, Indonesia)', Artibus Asiae, vol. 68, 2013, pp. 3-26.

Van Gulik, R.H. Siddham: An essay on the history of Sanskrit studies in China and Japan, New Delhi: International Academy of Indian Culture and Aditya Prakashan, 1980. [1956]

Guy, J., 'South Indian Buddhism and its Southeast Asian Legacy', in Pande, A., and Dhar, P.P. (eds.), Cultural Interface of India with Asia, Religion, Art and Architecture, New Delhi: D.K. Printworld/National Museum Institute, 2004, pp. 155-75.

Guy, J., 'Catalogue: Savior Cults', in Guy, J., Lost Kingdoms: Hindu-Buddhist Sculpture of Early Southeast Asia, New York/New Haven: The Metropolitan Museum of Art/Yale University Press, 2014, pp. 226-63. 
Hall, K.R., 'Indonesia's Evolving International Relationships in the Ninth to Early Eleventh Centuries: Evidence from Contemporary Shipwrecks and Epigraphy', Indonesia, vol. 90, 2010, pp. 15-45.

Hidas, G., Mahāpratisara-Mahāididyāraj̄ñ̄: The Great Amulet, Great Queen of Spells, New Delhi, 2012 .

Hodge, S. The Mahā-Vairocana-Abhisambodhi Tantra, with Buddhaguhya's commentary, New York: RoutledgeCurzon, 2003.

Holt, J., Buddha in the Crown: Avalokiteśvara in the Buddhist Traditions of Sri Lankāa, Oxford: Oxford University Press, 1991.

Jacq-Hergoualc'h, M., The Malay Peninsula: Crossroads of the Maritime Silk-Road (100 BC-1300 AD), Leiden: Brill, 2002

Jordaan, R., 'Tārā and Nyai Lara Kidul: Images of the divine feminine in Java', Asian Folklore Studies, vol. 2, no. 56, 1997, pp. 285-312.

Jordaan, R., 'The Tārā temple of Kalasan in Central Java', Bulletin de l'École française d'ExtrêmeOrient, vol. 85, 1998, pp. 163-83.

Jordaan, R., and Colless, B., 'The Ratu Boko mantra and the Sailendras', Berkala Arkeologi, vol. 24, no. 1, 2004, pp. 56-65.

Jordaan, R., and Colless, B., The Mahārāja of the Isles: The Sailendras and the Problem of Śrīvijaya, Leiden: Department of Languages and Cultures of Southeast Asia and Oceania, 2009

Kandahjaya, H., A study on the origin and significance of Borobudur, PhD dissertation, University of California, Berkeley, 2004.

Kandahjaya, H., 'The Lord of All Virtues', Pacific World: Journal of the Institute of Buddhist Studies (Third Series), vol. 11, 2009, pp. 1-25.

Kandahjaya, H., 'San் Hyan் Kamahāyānikan, Borobudur, and the Origins of Esoteric Buddhism in Premodern Indonesia', in A. Acri (ed.), Esoteric Buddhism in Mediaeval Maritime Asia: Networks of Masters, Texts, Icons, Singapore: ISEAS Publishing, 2016, pp. 67-112.

Kim, J., 'Local Visions, Transcendental Practices: Iconographic Innovations of Indian Esoteric Buddhism', History of Religions, vol. 54, no. 1, 2014, pp. 34-68.

Kimmet, N., 'Sharing Sacred Space: A Comparative Study of Tabo and Borobudur', in Bonatz, D., Reinecke, A., and Tjoa-Bonatz, M.L. (eds.), Selected Papers from the 13th International Conference of the European Association of Southeast Asian Archaeologists, Berlin, 2010, Volume 2: Connecting Empires and States, Singapore: National University of Singapore Press, 2012, pp. 93-101.

Kozok, U. (with Contributions by T. Hunter, W. Mahdi and J. Miksic), A 14th Century Malay Code of Laws: The Nītisārasamuccaya. Singapore: ISEAS Publishing, 2015. 
Kuijp, L.W.J. van der, 'A Treatise on Buddhist Epistemology and Logic attributed to Klong chen Rab 'byams pa (1308-1364) and Its Place in Indo-Tibetan Intellectual History', Journal of Indian Philosophy, vol. 31, 2003, pp. 381-437.

Lewis, M. and Wigen, K., The Myth of Continents: A Critique of Metageography, Berkeley: University of California Press, 1997.

Lienhard, S., Diamantmeister und Hausväter: buddhistisches Gemeindeleben in Nepal, Wien: Verlag der Österreichischen Akademie der Wissenschaften, 1999.

Lin, L.K., 'Punyyodaya (Na-t'i), un propagateur du tantrisme en Chine et au Cambodge à l'époque de Hiuan-tsang', Journal Asiatique, vol. 227, 1935, pp. 83-100.

Linrothe, R., Ruthless Compassion: Wrathful deities in early Indo-Tibetan esoteric Buddhist art, Boston: Shambhala, 1999.

Lobo, W., 'Reflections on the Tantric Buddhist Deity Hevajra in Cambodia', in Manguin, P.Y., (ed.), Southeast Asian Archaeology 1994. Proceedings of the 5th International Conference of the European Association of Southeast Asian Archaeologists; Paris, 24th-28th October 1994, Vol. 2, University of Hull: Centre for Southeast Asian Studies, 1994, pp. 113-27.

Lokesh Chandra, Buddhist Iconography in Nepalese Sketchbooks, New Delhi: Jayyed Press, 1984.

Lokesh Chandra, 'Oḍ̣ịāna: A New Interpretation', in T. Chandrika (ed.), Cultural Horizons of India, vol. 3, Delhi: South Asia Books, 1993a, pp. 491-514.

Lokesh Chandra, 'Evolutions of the Tantras', in T. Chandrika (ed.), Cultural Horizons Of India, Vol. 3, Delhi: South Asia Books, 1993b, pp. 7-139.

Lokesh Chandra, 'The Śailendras of Java', in Lokesh Chandra, Cultural Horizons of India, Vol. 4, New Delhi: International Academy of Indian Culture/Aditya Prakashan, 1995, pp. $205-41$.

Lokesh Chandra and Sudarshana Devi Singhal, 'The Buddhist bronzes of Surocolo', Cultural Horizons of India, Vol. 4, New Delhi: International Academy of Indian Culture/Aditya Prakashan, 1995, pp. 121-47.

Long, M., Voices from the Mountain: The Śailendra inscriptions discovered in Central Java and on the Malay Peninsula, New Delhi: International Academy of Indian Culture/Aditya Prakashan, 2014.

Lunsingh Scheurleer, P., 'The well-known Javanese Statue in the Tropenmuseum, Amsterdam, and its Place in Javanese Sculpture', Artibus Asiae, vol. 68, no. 2, 2008, pp. 287-332.

Majumdar, R.C., Ancient Indian colonies in the Far East, Vol. 2, Dacca: Ashok Kumar Majumdar, 1937.

Majumdar, R.C., (ed.) The History of Bengal, Volume I: Hindu Period. Lohanipur/Patna: N.V. Publications, 1971. [Reprint of first edition, 1943. Dacca: University of Dacca]

Malandra, G.H., Unfolding a mandala: The Buddhist cave temples at Ellora, Albany: State University of New York Press, 1993. 
Malandra, G.H., 'The Mandala at Ellora / Ellora in the Mandala', Journal of the International Association of Buddhist Studies, vol. 19, 1996, pp. 181-208.

Mevissen, G.J.R., 'Images of Mahāpratisarā in Bengal: Their Iconographic Links with Javanese, Central Asian and East Asian Images', Journal of Bengal Art, vol. 4, 1999, pp. 99-129.

Miksic, J.N., 'Double Meditation Platforms at Anuradhapura and the Pendopo of Ratu Boko', in Saraswati: Esai-Esai Arkeologi, No. 10, 1993-94, pp. 23-31 (Kalpataru, 2), Jakarta: National Research Centre for Archaeology.

Miksic, J.N., 'Mañjuśrī as a Political Symbol in Ancient Java', in B. Dagens and H. Chambert-Loir (eds.), Anamorphoses: Hommage à Jacques Dumarçay, Paris: Les Indes Savantes, 2006, pp. $185-226$.

Miksic, J.N., 'Archaeological Evidence for Esoteric Buddhism in Sumatra, 7th to 13th Century', in A. Acri (ed.), Esoteric Buddhism in Mediaeval Maritime Asia: Networks of Masters, Texts, Icons, Singapore: ISEAS Publishing, 2016, pp. 253-73.

Mishra, U., 'Dhāraṇīs from the Buddhist Sites of Orissa', Pratnatattva: Journal of the Dept. of Archaeology, Jahangirnagar University, vol. 22, 2016, pp. 73-84.

Mishra, U., Buddhism and maritime networks in early medieval coastal Orissa (5th century AD12th century AD), PhD Dissertation, Jawaharlal Nehru University, New Delhi, 2005.

Mishra, U., 'Vajrāyana Buddhism as a Religion of the Laity in Early Medieval Odisha (India)', in B.N. Prasad (ed.), Monasteries, Shrines \& Society: Buddhist and Brahmanical Religious Institutions in India in their Socio-Economic Context, New Delhi: Manak Publications, 2011, pp. 137-78.

Mitra, D., Buddhist monuments. (ed.) Sahitya Samsad, Calcutta, 1971.

Monius, A.E., Imagining a Place for Buddhism: Literary Culture and Religious Community in Tamil-Speaking South India, Oxford: Oxford University Press, 2001.

Mudiyanse, N. Mahāyāna Monuments of Ceylon, Colombo: M.D. Gunasena, 1967.

Neelis, J., Early Buddhist Transmission and Trade Networks: Mobility and Exchange within and beyond the Northwestern Borderlands of South Asia, Leiden/Boston: Brill, 2011.

Nihom, M., Studies in Indian and Indo-Indonesian Tantrism: The Kunjarakarnadharmakathana and the Yogatantra, Vienna: Sammlung De Nobili/Institut für Indologie der Universität Wien, 1994.

Nihom, M., 'The Maṇdala of Caṇdi Gumpung (Sumatra) and the Indo-Tibetan Vajraśekharatantra', Indo-Iranian Journal, vol. 41, 1998, pp. 245-54.

O’Brien, K., Means and Wisdom in Tantric Buddhist Rulership during the East Javanese Period, PhD dissertation, University of Sydney, 1993.

O’Brien, K., 'The Tale of Sudhana and Manohara- on Candi Jago: An Interpretation of a Series of Narrative Bas-reliefs on a 13th-Century East Javanese Monument', in A. Acri (ed.), Esoteric 
Buddhism in Mediaeval Maritime Asia: Networks of Masters, Texts, Icons, Singapore: ISEAS Publishing, 2016, pp. 275-320.

Orlina, R., 'Epigraphical evidence for the cult of Mahāpratisarā in the Philippines', Journal of the International Association of Buddhist Studies, vol. 35, no. 1-2, 2012, pp. 91-101.

Orzech, C.D., 'Legend of the Iron Stupa', in Lopez, D.S. Jr. (ed.), Buddhism in Practice, Princeton: Princeton University Press, 1995, pp. 314-17.

Orzech, C.D., 'Translation of Tantras and other Esoteric Buddhist scriptures', in Orzech, C.D., Sørensen, H.H., and Payne, R.K. (eds.), Esoteric Buddhism and the Tantras in East Asia, 2011 a, pp. 439-50.

Orzech, C.D. (gen. ed.), Sørensen, H.H., and Payne, R.K. (assoc. eds.), Esoteric Buddhism and the Tantras in East Asia, Leiden/Boston: Brill, $2011 \mathrm{~b}$.

Pandit, S., 'Ekādaśamukha Avalokiteśvara from Kanheri', in K.K. Naik and E. Siva Nagi Reddy (eds.), Cultural Contours of History and Archaeology, in honour of Snehasiri Prof. P. Chenna Reddy, Vol VII: Buddhism and Other Religions, Delhi: B.R. Publishing Corporation, 2015, pp. 58-64.

Patra, B., 'Connectivity and Beyond: Maritime Contacts of Kalinga with Java', Odisha Review (November), pp. 54-64. [Last accessed February 2016 at: http://odisha.gov.in/emagazine/Orissareview/2013/nov/engpdf/55-65.pdf

Patnaik, S.K. (ed.)., Buddhism and Maritime Heritage of South East Asia; Odishan Perspective, Bhubaneswar/Delhi: Odishan Institute of Maritime and South-East Asian Studies/Pratibha Prakashan, 2014.

Pollock, S., The language of the gods in the world of men: Sanskrit, culture, and power in premodern India, Berkeley: University of California Press, 2006.

Prapandvidya, C., 'The Sab Bāk Inscription: Evidence of an Early Vajrayāna Buddhist Presence in Thailand', Journal of the Siam Society, vol. 78, no. 2, 1990, pp. 11-14.

Ray, H.P., 'Providing for the Buddha: Monastic Centres in Eastern India', Arts Asiatiques, vol. 63, 2008, pp. 119-38.

Ray, H.P., 'Narratives of Travel and Shipwreck', in Skilling, P., and McDaniel, J. (eds.), Buddhist Narrative in Asia and Beyond, Vol. 2, Bangkok: Institute of Thai Studies and Chulalongkorn University, 2012, pp. 47-65.

Reichle, N. Violence and Serenity: Late Buddhist Sculpture from Indonesia, Honolulu: University of Hawai'i Press, 2007.

Reichle, N., 'Imagery, Ritual, and Ideology: Examining the Mahavihāira at Ratnagiri', in A. Acri (ed.), Esoteric Buddhism in Mediaeval Maritime Asia: Networks of Masters, Texts, Icons, Singapore: ISEAS Publishing, 2016, pp. 211-36. 
Revire, N., 'À propos d'une »tête " de khakkhara conservée au Musée national de Bangkok', Aséanie, vol. 24, 2009, pp. 111-34.

Revire, N., 'From Gandhara to Candi Mendut? A Comparative Study of Bhadrāsana Buddhas and Their Related Bodhisattva Attendants in South and Southeast Asia', draft of a paper presented at the seminar 'Cultural Dialogues Between India and South-East Asia from the 7th to the 16th Centuries', K.R. Cama Oriental Institute, Mumbai, January 17-18, $2015 a$.

Revire, N., 'New Perspectives on the Origin and Spread of Bhadrāsana Buddhas throughout Southeast Asia (7th-8th Centuries CE)' in. C. Lammerts (ed.), Buddhist Dynamics in Premodern and Early Modern Southeast Asia, Singapore: ISEAS Publishing, 2015b, pp. 12743.

Roerich, G.N. Blue Annals, 2 vols, Delhi: Motilal Banarsidass, 1953.

Sadakata, A., オリッサ州の仏教遺跡 (Buddhist Sites of Orissa), Proceedings of the Faculty of Letters of Tokai University, vol. 67, 1997, pp. 173-96.

Sanderson, A.G.J.S, 'Religion and the State: Śaiva Officiants in the Territory of the Brahmanical Royal Chaplain with an Appendix on the Provenance and Date of the Netratantra', IndoIranian Journal, vol. 47, 2004, pp. 229-300.

Sanderson, A.G.J.S, The Śaiva Age-The Rise and Dominance of Śaivism during the Early Medieval Period', in S. Einoo (ed.), Genesis and Development of Tantrism, Tokyo: Institute of Oriental Culture, University of Tokyo, 2009, pp. 41-350.

Sankrityayana, R., 'Recherches Bouddhiques: Les Origines du Mahāyāna et du Vajrayāna et les 84 Siddhas', Journal Asiatique, vol. 22, 1934, pp. 195-230.

Saran, S.C., 'Vikramśsilā University-A Centre of Tantricism', in J.S. Jha (ed.), K.P. Jayaswal Commemoration Volume, Patna: K.P. Jayaswal Research Institute, 1981, pp. 117-22.

Sarkar, H.B., Cultural relations between India and Southeast Asian countries, New Delhi: Indian Council for Cultural Relations/Motilal Banarsidass, 1985a.

Sarkar, H.B., 'The Kings of Srī Sailam and the foundation of the Sailendra Dynasty of Indonesia', Bijdragen tot de Taal-, Land- end Volkenkunde 141, 1985b, pp. 323-38.

Sarkar, H.B., Corpus of the Inscriptions of Java. 2 vols., Calcutta: Firma K. L. Mukhopadhyay, 1971.

Sastri, H., 'The Nālandā copperplate of Devapāladeva', in R.B.H. Krishna Sastri (ed.), Epigraphia Indica, vol. 17, Calcutta: Manager, Government of India Central Publication Branch, 192324, pp. 310-27.

Schoterman, J., 'A surviving Amoghapāśa sādhana: Its relation to the five main statues of Candi Jago', in Klokke, M.J., and Lunsingh Scheurleer, P., (eds.), Ancient Indonesian Sculpture, Leiden: KITLV Press, 1994, pp. 154-77. 
Schoterman, J. 'Traces of Indonesian Influences in Tibet', in A. Acri (ed.), Esoteric Buddhism in Mediaeval Maritime Asia: Networks of Masters, Texts, Icons, Singapore: ISEAS Publishing, 2016, pp. 113-22. [Original edition: Indonesische Sporen in Tibet, Leiden: Brill, 1986.]

Schroeder, U. von, Indo-Tibetan Bronzes. Hong Kong: Visual Dharma Publications, 1981.

Sen, T., Buddhism, Diplomacy, and Trade: The realignment of Sino-Indian Relations, 600-1400, Honolulu: Association for Asian Studies/University of Hawai'i press, 2003.

Sen, T., 'Buddhism and the Maritime Crossings', in D.C. Wong and G. Heldt (eds.), China and Beyond in the Mediaeval Period: Cultural Crossings and Inter-Regional Connections, Singapore/New Delhi: ISEAS Publishing/Manohar, 2014a, pp. 39-62.

Sen, T., 'Introduction: Buddhism in Asian History', in T. Sen (ed.), Buddhism Across Asia: Networks of Material, Intellectual, and Cultural Exchange, Vol. 1, Singapore/New Delhi: ISEAS Publishing/Manohar, 2014b, pp. xi-xxx.

Seshadri, G., 'New Perspectives on Nagapattinam, The Medieval Port City in the Context of Political, Religious, and Commercial Exchanges between South India, Southeast Asia, and China', in Kulke, H., Kesavapany, K., and Sakhuja, V., (eds.), Nagapattinam to Suvarnadwipa: Reflections on the Chola Naval Expeditions to Southeast Asia, Singapore: ISEAS Publishing, 2009, pp. 102-34.

Sharma, N., 'Surocolo Bronzes and their Tantric Text', Acta Orientalia Academiae Scientiarum Hungaricae, vol. 64, 2011, pp. 209-19.

Sharrock, P.D., 'Hevajra at Bantéay Chmàr', The Journal of the Walters Art Museum, vols. 64-65, 2006, pp. 49-64.

Sharrock, P.D., 'The Mystery of the Bayon Face Towers', in J. Clark (ed.), Bayon: New Perspectives, Bangkok: River Books, 2007, pp. 230-81.

Sharrock, P.D., 'Garuḍa, Vajrapāṇi and religious change in Jayavarman VII's Angkor', Journal of Southeast Asian Studies, vol. 40, 2009, pp. 111-51.

Sharrock, P.D., 'Discussion on Vajrasattva of Barong Lovéa Em, Kandāl (K.5432, E.808)', Appendix 4 in E.C. Bunker and D. Latchford (eds.), Khmer Bronzes: New Interpretations of the Past, Chicago: Art Media Resources, 2011, pp. 493-96.

Sharrock, P.D., 'Kīrtipandita and the Tantras: The revival of Buddhism in 10th century Angkor', Udaya, vol. 10, 2012, pp. 203-37.

Sharrock, P.D., 'The Tantric Roots of the Buddhist Pantheon of Jayavarman VII', in M.J. Klokke and V. Degroot (eds.), Materializing Southeast Asia's past: selected papers of the 12th international conference of the European Association of Southeast Asian Archaeologists, Vol. 2, Singapore: NUS Press, 2013a, pp. 41-55.

Sharrock, P.D., 'The Yoginīs of the Bayon', in I. Keul (ed.) 'Yogin̄̄' in South Asia: Interdisciplinary Approaches, London and New York: Routledge, 2013b, pp. 117-30. 
Sharrock, P.D., and Bunker, E., 'Seeds of Vajrabodhi: Buddhist Ritual Bronzes from Java and Khorat', in A. Acri (ed.), Esoteric Buddhism in Mediaeval Maritime Asia: Networks of Masters, Texts, Icons, Singapore: ISEAS Publishing, 2016, pp. 237-54.

Shinohara, K., Spells, Images, and Maṇdalas: Tracing the Evolution of Esoteric Buddhist Rituals, New York: Columbia University Press, 2014.

Sinclair, I., 'Vajrācāryas, monks or bust: Divergent Buddhisms in Sanskritic Asia, 900-1900 CE', draft paper (unpublished) presented at the Workshop 'Orders and Itineraries: Buddhist, Islamic, and Christian Networks in Southern Asia, c. 900-1900', Asia Research Institute (NUS), February 2012 [Draft dated 2013].

Sinclair, I., 'Coronation and Liberation According to a Javanese Monk in China: Bianhong's Manual on the abhiseka of a cakravartin', in A. Acri (ed.), Esoteric Buddhism in Mediaeval Maritime Asia: Networks of Masters, Texts, Icons, Singapore: ISEAS Publishing, 2016a, pp. 29-66.

Sinclair, I., 'Appendix A: The Names of Nagabuddhi and Vajrabuddhi', in A. Acri (ed.), Esoteric Buddhism in Mediaeval Maritime Asia: Networks of Masters, Texts, Icons, Singapore: ISEAS Publishing, 2016b, pp. 389-91.

Skilling, P. 'Dharmakīrti's Durbodhāloka and the Literature of Śrivijaya ,'Journal of the Siam Society, vol. 85, 1997, pp. 187-94.

Skilling, P., 'Geographies of Intertextuality: Buddhist Literature in pre-modern Siam', Aséanie, vol. 19, 2007, pp. 91-112.

Skilling, P., 'Pieces in the puzzle: Sanskrit literature in pre-modern Siam', in C. Cicuzza (ed.), Buddhism and Buddhist Literature of South-East Asia; Selected Papers, Bangkok and Lumbini: Fragile Palm Leaves Foundation \& Lumbini International Research Institute, 2009, pp. 27-45.

Skilling, P., 'An Untraced Buddhist Verse Inscription from Peninsular Southeast Asia', in D.C. Lammerts (ed.), Buddhist Dynamics in Premodern and Early Modern Southeast Asia, Singapore: ISEAS Publishing, 2015, pp. 18-79.

Sprengard, K.A. and Ptak, R., 'Preface', in K.A. Sprengard and R. Ptak (eds.), Maritime Asia: Profit Maximisation, Ethics and Trade Structure, pp. vii-xi, Wiesbaden: Harrassowitz Verlag, 1994.

Sugiki, T., 'Chakurasanvaratantorano Seiritsu Dankai ni tsuite: Oyobi Jayabhadra saku Śrīcakrasaṃvarapañjikā Kōtei Bonpon', Chisan Gakuhō, vol. 50, 2001, pp. 91-141.

Sundberg, J.R., 'A Buddhist mantra recovered from the Ratu Baka plateau: A preliminary study of its implications for Śailendra-era Java', Bijdragen tot de Taal-, Land- en Volkenkunde, vol. 159, 2003, pp. 163-88. 
Sundberg, J.R., "The wilderness monks of the Abhayagirivihāra and the origins of Sino-Javanese esoteric Buddhism', in Bijdragen tot de Taal-, Land-en Volkenkunde, vol. 160, 2004, pp. 95-123.

Sundberg, J.R., 'The Abhayagirivihāra's pāṃśukūlika monks in Second Lambakaṇna Śrī Lañkā and Śailendra Java: The efflorescence and fall of a center of influence in early Esoteric Buddhism', Pacific World: Journal of the Institute of Buddhist Studies (Third Series), vol. 12, 2014 (appeared 2015), pp. 49-185.

Sundberg, J., 'Mid-9th-Century Adversity for Sinhalese Esoteric Buddhist Exemplars in Java: Lord Kumbhayoni and the 'Rag-wearer' Pamsukulika Monks of the Abhayagirivihära', in A. Acri (ed.), Esoteric Buddhism in Mediaeval Maritime Asia: Networks of Masters, Texts, Icons, Singapore: ISEAS Publishing, 2016b, pp. 349-80.

Sundberg, J. (in collaboration with Giebel, R.), 'The Life of the Tang Court Vajrabodhi as Chronicled by Lü Xiang (呂向): South Indian and Śrī Lañkān Antecedents to the Arrival of the Buddhist Vajrayāna in Eighth-Century Java and China', Pacific World: Journal of the Institute of Buddhist Studies (Third Series), vol. 13, 2011, pp. 129-222.

Szántó, P.D., 'Some unknown/unedited fragments of Cakrasamvara literature', handout distributed at the conference 'Transgression and Encounters with the Terrible in Buddhist and Saiva Tantras', University of Zurich, 19-20 February, 2016.

Szántó, P.D., 'Vāgīśvarakīrti', in D. Goodall et al. (eds.), Saivism and the Tantric Traditions: Essays in Honour of Alexis Sanderson, Leiden/Boston: Brill, forthcoming.

Szántó, P.D., and A. Griffiths, "Sarvabuddhasamāyogaḍākinījālaśaṃvara,” in J.A. Silk, O. v. Hinüber, \& V. Eltschinger, eds., Brill's Encyclopedia of Buddhism, Vol. 1, Leiden, 2015 , pp. 988-1009.

Tanaka, K. 'Nālandā as a Centre of Esoteric Buddhism', in C. Mani (ed.), The Heritage of Nalanda, New Delhi: Asoka Mission, 2008, pp. 93-95.

Tanaka, K., Indo ni okeru mandara no seiritsu to hatten インドにおける曼茶羅の成立と発 展 (Genesis and development of the maṇula in India), Tokyo: Shunjūsha, 2010.

Tanaka，K.，オリッサ州ウダヤギリ I出土の石刻陀羅尼について ('A Newly Identified Dhāraṇī-sūtra from Udayagiri II'), The Memoirs of Institute for Advanced Studies on Asia, vol. 166, 2014, pp. $124(161)-34(151)$.

Yamano, C., 'Śrīparvata as Nāgārjuna's Abode: At the confluence of legend, history, and geography', Journal of Indian and Buddhist Studies, vol. 57, no. 3, 2009, pp. 1246-52.

Wang Gungwu, in Ooi Kee Beng, The Eurasian Core and its Edges: Dialogues with Wang Gungwu on the History of the World, Singapore: ISEAS Publishing, 2015.

Wayman, A., 'Reflections on the theory of Barabudur as a Mandala', in Gomez, L., and Woodward, H.W. Jr., (eds.), Barabudur: History and Significance of a Buddhist Monument, Berkeley: Asian Humanities Press, 1981, pp. 139-72. 
Wayman, A. and Tajima, R., The Enlightenment of Vairocana, Delhi: Motilal Banarsidass, 1992.

White, D.G., The Alchemical Body: Siddha Traditions in medieval India. Chicago and London: The University of Chicago Press, 1996.

White, D.G., 'Introduction; Tantra in Practice: Mapping a Tradition', in D.G. White (ed.), Tantra in Practice, Princeton/Oxford: Princeton University Press, 2000, pp. 3-38.

White, D.G., 'Netra Tantra at the Crossroads of the Demonological Cosmopolis', Journal of Hindu Studies, vol. 5, 2012, pp. 145-71.

Wilkinson, C. 'The Tantric Ganesa: Texts Preserved in the Tibetan Canon', in R. Brown (ed.), Ganesh: Studies of an Asian God, Albany: SUNY Press, 1991, 235-75.

Wolters, O.W., History, Culture and Region in Southeast Asian Perspectives, Second Edition, Singapore: Institute of Southeast Asian Studies, 1999.

Wong, D.C. and G. Heldt, 'Introduction: Cultural Crossings', in D.C. Wong and G. Heldt (eds.), China and Beyond in the Mediaeval Period: Cultural Crossings and Inter-Regional Connections, Singapore/New Delhi: ISEAS Publishing/Manohar.

Woodward, H.W., 'A Chinese silk depicted at Candi Sewu', in: K.L. Hutterer (ed.), Asia: Perspectives from prehistory, history, and ethnography, Ann Arbor: The University of Michigan, Center for South and Southeast Asian Studies, 1977, pp. 233-43.

Woodward, H.W., 'Tantric Buddhism at Angkor Thom', Ars Orientalis, vol. 12, 1981, pp. 57-67.

Woodward, H.W., 'Southeast Asian traces of the Buddhist pilgrims', Muse: Annual of the Museum of Art and Archaeology, University of Missouri-Columbia, vol. 22, 1988, pp. 75-91.

Woodward, H.W., 'The Life of the Buddha in the Pala Monastic Environment', The Journal of the Walters Art Gallery, vol. 48, 1990, pp. 13-27.

Woodward, H.W., ‘On Borobudur's upper terraces', Oriental Art, vol. 45, no. 3, 1999, pp. 34-43.

Woodward, H.W., 'Review article: Esoteric Buddhism in Southeast Asia in the Light of Recent Scholarship', Journal of Southeast Asian Studies, vol. 35, no. 2, 2004, pp. 329-54.

Woodward, H.W., 'Bianhong, Mastermind of Borobudur?', Pacific World: Journal of the Institute of Buddhist Studies (Third Series), vol. 11, 2009, pp. 25-60.

Woodward, H.W., 'The temple of Dong Duong and the Kāraṇdavyūha Sūtra', in Manjushree (ed.), From Beyond the Easter Horizon; Essays in Honour of Professor Lokesh Chandra, New Delhi: Aditya Prakashan, 2011, pp. 33-42. 